\title{
A retração no mercado de trabalho da construção (2012-2019): Brasil e RMSP
}

The contraction in the construction labor market (2012-2019): Brazil and the Metropolitan Region of São Paulo

\author{
Juliana Bacelar de Araújo [I] \\ Cassiano José Bezerra Marques Trovão [II]
}

\section{Resumo}

O objetivo deste artigo é analisar a retração no mercado de trabalho da construção, entre 2012 e 2020, no Brasil e na Região Metropolitana de São Paulo - RMSP, focando no subsetor de Construção de Edifícios. Observou-se uma forte retração no número de empregos formais na Construção de Edifícios, com aumento do peso da ocupação por conta própria, da informalidade e da participação dos trabalhadores com menor remuneração, inclusive na RMSP. A crise de 2015-2016 acentuou esse movimento, aumentando a precarização do trabaIho, não equacionado pela reforma trabalhista ou pela lenta recuperação após 2017, baseada na criação de postos de trabalho de baixa remuneração. A pandemia impactou significativamente o setor, evidenciando a necessidade de melhorias nas suas relações e condições de trabalho.

Palavras-chave: mercado de trabalho; indústria da construção; mercado imobiliário; Brasil; Região Metropolitana de São Paulo.

\begin{abstract}
The objective of the article is to analyze the contraction in the construction labor market in Brazil and in the Metropolitan Region of São Paulo (MRSP) between 2012 and 2020, focusing on building construction. We observed a strong decrease in the number of formal jobs in this subsector, with an increase in the weight of selfemployment, informality, and in the participation of lower-paid workers, even in the MRSP. The 2015-2016 crisis accentuated this movement, increasing the precarization of labor, not addressed by the labor reform nor by the slow recovery after 2017, which was based on the creation of low-paying jobs. The pandemic had a significant impact on the sector, highlighting the necessity of improvements in its working relationships and conditions.
\end{abstract}

Keywords: labor market; construction industry; real estate; Brazil; Metropolitan Region of São Paulo. 


\section{Introdução - Dinâmica setorial da Construção}

A partir de 2004, observa-se a retomada do crescimento do produto da economia brasileira, com manutenção das políticas macroeconômicas, mas em um contexto internacional favorável. Esse dinamismo foi puxado, inicialmente, pelo incremento das exportações e, em seguida, pela expansão do consumo interno, do crédito e do investimento e do rendimento médio das famílias, além da consolidação das políticas sociais e da implementação da política de valorização do salário-mínimo. Contudo, esse cenário se reverte a partir do final de 2008 e início de 2009, com os impactos da crise financeira internacional sobre a economia brasileira. Com a adoção de medidas anticíclicas, a economia recuperou-se em 2010. Do ponto de vista do mercado de trabalho, importantes avanços podem ser verificados nesse período, com destaque para a forte redução da taxa de desemprego/desocupação, a expansão significativa do emprego formal e a elevação dos rendimentos reais médios do trabalho.

A Indústria da Construção ${ }^{1}$ também seguiu esse movimento, apresentando forte expansão de sua atividade, especialmente entre 2004 e 2008, reflexo da ampliação do crédito e da renda das famílias e da retomada dos investimentos público e privado em infraestrutura econômica e social, em particular, por conta do Programa de Aceleração do Crescimento (PAC). Em 2004, o Valor Adicionado Bruto (VAB) da Construção apresentou uma taxa de crescimento maior que a do Produto Interno Bruto (PIB), como é possível observar através dos dados do Gráfico 1. Esse setor, também, foi impactado pela retração de 2009, apresentando uma queda do Valor Adicionado Bruto maior que a média do PIB. A Construção apresentou as maiores taxas de crescimento da ocupação nos anos 2000, dentre os principais

Gráfico 1 - Taxa média de crescimento anual do PIB e do Valor Adicionado Bruto da Construção. Brasil, 2004-2019

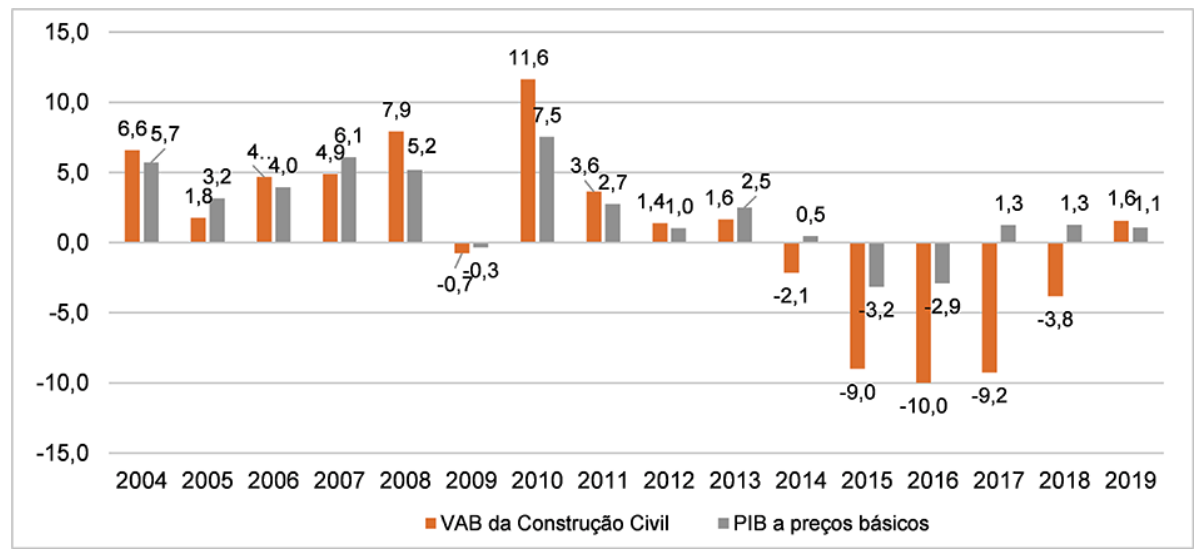

Fonte: IBGE - Sistema de Contas Nacionais Referência 2010. Elaboração: Ipeadata/Dimac. 
setores, com expressivo incremento do emprego formal e melhorias no nível de escolaridade e rendimento médio de seus trabalhadores, especialmente entre as mulheres. Contudo, ainda se mostra um setor marcado pela predominância do trabalho masculino, com baixo nível de escolaridade, alto grau de rotatividade e grande peso da ocupação por conta própria (Araújo e Prado, 2015).

A partir de 2010, com a implementação de um conjunto de políticas e incentivos, o setor recuperou-se impulsionado fortemente pela implementação da segunda etapa do PAC que incorporou novas ações de infraestrutura social e urbana para, segundo divulgado, enfrentar os problemas das grandes cidades brasileiras (PAC/MPOG, 2014). O PAC 2 foi dividido em 6 eixos: transportes, energia, cidade melhor, comunidade cidadã, água e luz para todos, assim como do Programa Minha Casa Minha Vida (PMCMV). O PMCMV, além de se apresentar como uma política anticíclica, também favoreceu os interesses do setor imobiliário, acenando para a habitação como estratégia econômica, ideológica e política (Mioto, 2015). Vale ressaltar que a taxa anual de crescimento de $11,6 \%$ do Valor Adicionado Bruto da Construção (Gráfico 1), em 2010, foi o melhor desempenho do setor desde os anos 1990 (Dieese, 2011).

Entretanto, entre 2012 e 2014, verificou-se um processo de desaceleração da atividade econômica, com expressiva queda das taxas de crescimento do PIB, refletindo, em termos macroeconômicos, a persistência dos efeitos da crise mundial (com fraca recuperação da economia Europeia e a continuidade do declínio dos preços das commodities), bem como as limitações dos mecanismos desenvolvidos para a retomada da atividade econômica nacional.
A Construção seguiu a dinâmica geral e refletiu também os desdobramentos da Operação "Lava Jato", a desaceleração do PMCMV e a queda dos investimentos. Segundo Orair (2016), já possível de se observar, em 2014, com a retração dos investimentos públicos das estatais federais. A Construção apresentou em 2014 uma retração do Valor Adicionado Bruto setorial de $-2,1 \%$.

A partir de 2015, com a adoção de políticas de austeridade econômica que, segundo Rossi e Mello (2017), contemplava um conjunto de choques: fiscal (retração das despesas públicas em termos reais), de preços administrados (especialmente de combustíveis e energia), cambial (desvalorização de $50 \%$ da moeda brasileira em relação ao dólar ao longo de 2015) e monetário (aumento das taxas de juros para operações de crédito). Esse movimento resultou em forte queda no consumo das famílias, aumento do endividamento e mudanças no mercado de trabalho, em especial no urbano, com forte e rápido crescimento da desocupação e da informalização. De acordo com Pinto et al. (2017, p. 14), é possível observar que a "crise de acumulação e realização foi atravessada pela crise política e, sobretudo, institucional a partir dos efeitos da Operação Lava Jato". O resultado foi uma crise econômica que se juntaria à crise política e institucional, levando o País a uma das maiores crises socioeconômicas de sua história. De 2017 em diante, observa-se um cenário de baixo crescimento e lenta "recuperação" da atividade econômica que perduraria até 2019. No ano de 2020, o País viria a enfrentar (e ainda enfrenta, até o momento em que este texto é escrito), uma crise sanitária, de saúde pública, econômica e social, de proporções nunca antes vistas, provocada pela pandemia da Covid-19. 
Nesse contexto, deve-se destacar que o setor da Construção apresentou retração do Valor Adicionado Bruto setorial por quatro anos consecutivos após 2015, com quedas superiores à própria queda do Produto Interno Bruto total. Mesmo com a lenta retomada da atividade econômica, a partir de 2017, esse setor ainda não se recuperou, reflexo da falta de investimentos na economia (os níveis de Formação Bruta de Capital Fixo permanecem baixos), da deterioração do mercado de trabaIho e da perda de renda das famílias. Apenas em 2019, o setor voltaria a apresentar crescimento do Valor Adicionado Bruto, mas, ainda, bastante modesto em relação à queda sofrida nos últimos anos. Esse movimento pode ser observado a partir da participação do setor no PIB, que chegou a ser de 6,5\%, em 2012, e retraiu para $3,7 \%$, em 2019 , segundo os dados do IBGE.
Para se ter uma dimensão dos movimentos do setor nos subperíodos destacados, pode-se observar que, entre 2004 e 2011, o Valor Adicionado Bruto da Construção apresentou um crescimento acumulado de $47,6 \%$. Já, entre 2012 e 2014, nota-se uma relativa estabilidade ( $+0,8 \%$ no acumulado do período), e, no período que se estende de 2015 a 2019, houve uma retração acumulada de $-27,4 \%$.

Outro fator importante para desempenho do setor ao longo das primeiras décadas do século XXI esteve associado aos movimentos dos financiamentos imobiliários, concedidos pelo FGTS e pela Poupança-SBPE (Sistema Brasileiro de Poupança e Empréstimo). 0 volume desses financiamentos cresceu expressivamente até 2011, chegando a um aporte de recurso de $\mathrm{R} \$ 1$ 186,5 bilhões (Gráfico 2). No período de desaceleração, entre 2012 e 2014, observam-se uma queda e, depois, um

Gráfico 2 - Financiamentos imobiliários concedidos pelo SBPE e FGTS em R\$ milhões (a preços de 2020 - IPCA). Brasil, 2004-2020

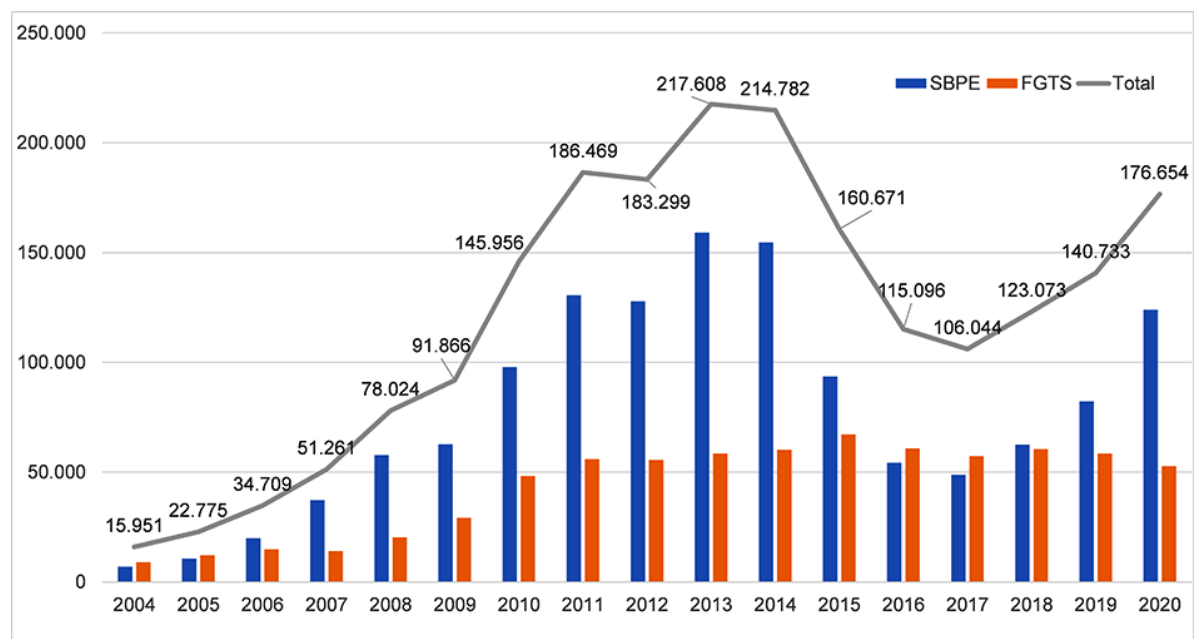

Fonte: Abecip e Banco Central; CBIC e Caixa Econômica Federal. 
aumento do volume de financiamentos, para patamares superiores aos anos precedentes. Porém, a crise de 2015 impactou negativamente essas fontes de financiamento, derrubando significativamente os recursos, sobretudo do SBPE, que só se recuperaria a partir de 2018. Esse movimento se manteve, mesmo em 2020, a despeito dos efeitos da pandemia.

Segundo o Dieese (2020, p. 2),

O crédito para a Construção Civil voltou a crescer em 2018, puxado inicialmente pelo crédito para pessoas jurídicas (empresas). 0 crédito para pessoas físicas tem apresentado uma recuperação mais lenta. Contudo, a participação do crédito para pessoa física é bastante relevante, uma vez que representa em torno de $86 \%$ do crédito total para o setor, com destaque para os recursos do Sistema Financeiro da Habitação (SFH) e do Fundo de Garantia do Tempo de Serviço (FGTS).

Em relação aos subsetores da Construção, segundo dados da Pesquisa Anual da Indústria da Construção (Paic), do IBGE, observa-se maior importância dos subsetores de Construção de Edifícios e obras de infraestrutura para a composição do Valor Bruto da Produção (VBP) setorial brasileira. A partir de 2012, com a desaceleração do setor, é possível notar uma perda de participação no VBP das obras de infraestrutura, em contrapartida ao ganho do subsetor de Construção de Edifícios, que atinge o patamar de 45\%, entre 2015 e 2016.

Como destacado por Mioto, Castro e Sígolo (2019, p. 254),

embora tenha sofrido transformações técnicas significativas, ainda é um setor considerado intensivo em força de trabaIho, sendo o subsetor de edificações um importante vetor de dinamismo do mercado de trabalho urbano. A construção ainda mobiliza uma miríade de segmentos ligados aos insumos de produção, máquinas e equipamentos, acabamento, etc. Além de seus efeitos diretos no emprego e na renda e de encadeamento industrial, somam-se os ganhos conectados ao financiamento e crédito bancário e aqueles derivados da propriedade, ou seja, de natureza rentista. Considerando o período mais recente, destaca-se, também, a crescente imbricação das finanças nas determinações das decisões empresariais e produtivas do setor, fazendo com que novos agentes, como seguradoras, fundos de investimento, bancos de investimento, etc., passem a comandar as decisões e os ganhos.

Em termos regionais, deve-se destacar, nesse processo, a importância de São Paulo para o setor de Construção. Segundo os dados do IBGE, o estado de São Paulo perdeu participação relativa no Valor Adicionado Bruto da Construção nacional até 2012, chegando a $26,8 \%$, o que reflete um movimento de desconcentração observado no setor, na primeira década dos anos 2000. A partir da desaceleração econômica, após 2012, é possível observar um pequeno crescimento e uma relativa estabilidade de sua participação em torno de $27,5 \%$, inclusive durante a crise de 2015 e 2016. Em 2017, a participação de São Paulo chegou a $28,9 \%$ do Valor Adicionado Bruto da Construção nacional e a $28,3 \%$, em 2018. Dentro do estado, o subsetor da Construção de Edifícios mostra-se mais expressivo na Região Metropolitana de São Paulo (RMSP), área mais densamente povoada do estado, na qual o mercado imobiliário é bastante consolidado. Como apontado por Mioto, Castro e Sígolo (ibid.) e Penha Filho (2020), na fase de expansão do setor, as grandes incorporadoras avançaram com lançamentos nos municípios 
periféricos da RMSP. Já, na desaceleração da atividade imobiliária, eles voltam-se para a produção na cidade de São Paulo e em produtos de menor escala.

Em resumo, a Construção, que apresentou forte expansão no início dos anos 2000, a partir de 2012, seguiu a tendência geral da economia, ao passar pelo mesmo processo de desaceleração da sua atividade, que culminaria na forte queda dos investimentos, em retração desde 2014. A partir de 2015, o setor apresentou sucessivas taxas negativas de incremento do Valor Adicionado Bruto, recuperando-se apenas a partir de 2019, puxado sobretudo pela retomada da atividade em áreas e mercados mais consolidados, como é o caso da RMSP e do subsetor de Construção de Edifícios. Especificamente para a Região Metropolitana de São Paulo, Lencioni (2014) aponta para processos de concentração e centralização do capital no mercado imobiliário. A "expansão da magnitude dos capitais envolvidos no setor imobiliário, o crescimento do número de fusões, a multiplicação das formas de financiamento das empresas, incluindo-se aí a estratégia de abertura de ações na bolsa de valores", todos esses foram elementos importantes para a reestruturação imobiliária, que apresenta, ainda de acordo com a autora, forte integração entre o setor imobiliário e o financeiro (ibid., p. 44).

Uma nova ruptura ocorreria em 2020, a partir dos impactos da crise sanitário-econômica mundial da Covid-19, mostrando o quão fundamental se mostram a recuperação do crescimento da atividade econômica nacional, após a superação da pandemia, e a elevação dos investimentos públicos e privados em infraestrutura econômica e social, para que se consiga reativar um dos setores mais relevantes do ponto de vista da geração de empregos e renda.
Contudo, é necessário avançar na regulação e na estruturação da parcela do mercado de trabalho que compete a esse setor. Como ressalta o Dieese (2014, p. 61),

na Indústria da Construção, o atraso histórico das relações de trabalho, a ausência de ação propositiva e fiscalizatória do Estado no enfrentamento das questões centrais que têm impactos sobre o setor informalidade, rotatividade, terceirização, saúde e segurança - são os principais desafios a serem vencidos de forma a estabelecer relações e condições de trabalho decentes para os trabalhadores.

0 presente artigo tem como objetivo analisar o movimento mais geral de retração no mercado de trabalho da construção, entre 2012 e 2020, no Brasil e na RMSP, focando no subsetor de Construção de Edifícios. Ele está estruturado em 5 seções, além desta introdução. Na primeira, analisa-se a dinâmica geral do mercado de trabalho no Brasil e na RMSP de 2012 e 2019, a partir dos dados da Pnad Contínua do IBGE. Na segunda, parte-se das transformações que ocorreram no setor para aprofundar o estudo da ocupação na Construção e no subsetor da Construção e incorporação de edifícios, comparando os movimentos para o Brasil e para a RMSP nesse mesmo período. Em seguida, detalha-se a retração do emprego formal na Construção de Edifícios no Brasil e na RMSP, com base nos dados da Relação Anual de Informações Sociais (Rais) e do Cadastro Geral de Emprego e Desemprego (Caged), do antigo Ministério do Trabalho. Na quarta seção, alguns dados são apresentados para mostrar essa ruptura provocada pela pandemia da Covid-19 em 2020 e seus impactos sobre o mercado de trabalho da Construção. Por fim, são feitas algumas considerações finais. 


\section{Dinâmica geral do mercado de trabalho no Brasil e na RMSP}

Quando emergiram e aceleraram os processos de globalização, financeirização e reestruturação produtiva, a partir dos anos 1980 e 1990, o mercado de trabalho brasileiro caracterizava-se por uma ampla heterogeneidade e forte fragmentação. Diferentemente dos países desenvolvidos, a modernização havia gerado, no Brasil, um grau de assalariamento relativamente baixo, poucas mudanças na organização social - os sindicatos não tiveram tanta força para reivindicar um maior grau de ocupação assalariada - e não se tinha conseguido resolver os problemas estruturais (questões agrárias, regionais, urbanas e sociais) que caracterizavam o País (Dedecca e Baltar, 1997).

No início dos anos 2000, presenciam-se um processo de reconfiguração do mercado de trabalho nacional, com significativo aumento do trabalho com carteira assinada, expressiva queda da taxa de desemprego e melhorias nos rendimentos médios do trabalho. Tendência esta que seria revertida na segunda década dos anos 2000. Todavia, independentemente do contexto, esse mercado de trabalho continuou sendo caracterizado por uma grande heterogeneidade e pela manutenção do alto peso relativo do trabalho por conta própria e sem carteira de trabalho assinada.

Considerando mercados de trabalho estruturalmente heterogêneos e com elevados contingentes de trabalhadores ocupados no setor informal, como é o caso de países ou regiões periféricas como o Brasil, é importante que se faça uma análise mais ampla, para além dos tradicionais indicadores de mercado de trabalho. A Pesquisa Nacional por Amostra de Domicílios Contínua (Pnad-C), a partir de 2012, passou a contemplar, em seu questionário, perguntas capazes de mensurar fenômenos como: 1) a subocupação por insuficiência de horas trabalhadas, os chamados "bicos", que, em parte, foram institucionalizados e legalizados, a partir da reforma trabalhista de 2017, na forma de trabalhos intermitentes; ${ }^{2} \mathrm{e}$ 2) o desalento, situação na qual o trabalhador desiste de procurar trabalho por desestímulos de distintas ordens. ${ }^{3}$ Em tais contextos, faz-se necessária uma avaliação mais cuidadosa do que se denomina Subutilização ${ }^{4}$ da Força de Trabalho que, além desses dois fenômenos, incorpora a desocupação e as pessoas que não estavam disponíveis para trabalhar na semana de referência, mas gostariam de ocupar um posto de trabalho. Ao considerar todos esses elementos, amplia-se o conceito de força de trabalho, contemplando-se pessoas com potencial para trabalhar, o que configura a chamada força de trabalho ampliada. ${ }^{5}$

Todos esses fenômenos guardam estreita relação com a dinâmica da atividade produtiva. O Brasil, no início da década de 2010, entrou em uma fase de desaceleração econômica (2012 a 2014), na qual se observa que o comportamento da desocupação no País como um todo manteve uma tendência de queda, já observada no período de expansão (20042011), ainda que em menor ritmo. Esse mesmo comportamento não pôde ser observado para a RMSP, na qual se verifica uma tendência de elevação da taxa de desocupação já a partir de 2012, com relativa estabilidade da subutilização da força de trabalho. Tal trajetória reforça a ideia de que o mercado de trabalho tem seu desempenho atrelado à dinâmica econômica. Isso fica ainda mais claro no período de crise (2015-2016) e de lenta recuperação 
econômica (2017-2019), quando as taxas de desocupação e de subutilização da força de trabalho se ampliam significativamente.

Nessa fase, observa-se uma elevação da desocupação e da subutilização da força de trabalho, tanto no Brasil quanto na RMSP, especialmente até 2017. A lenta recuperação da atividade produtiva que se seguiu não foi capaz de proporcionar melhoras significativas no mercado de trabalho nacional que, apesar de ter reduzido a taxa de desocupação e a taxa de subutilização, não retornaram aos patamares observados no período pré-crise, permanecendo elevadas até 2019. Contudo, destaca-se que, na RMSP, tanto a subutilização da força de trabalho quanto a desocupação se reduziram em ritmo mais acelerado que a média nacional, entre 2018 e 2019.

Chama a atenção que a RMSP apresentou, historicamente, taxas de desocupação superiores à média nacional. Porém, quanto à subutilização, essa região se mostrou menos desfavorável aos trabalhadores. Isso se deve ao fato de a RMSP apresentar menores proporções de subocupados e de desalentados, comparativamente ao total da força de trabalho. $\mathrm{Na}$ RMSP, o desemprego de longo prazo é relativamente menor que a média do Brasil, e a própria dinâmica do mercado de trabalho mostra-se menos desfavorável aos trabalhadores, do ponto de vista da percepção de se conseguir um posto de trabalho, o que ameniza os efeitos dos fenômenos da subocupação e do desalento.

Como apontado anteriormente, a informalidade é outro fenômeno característico do mercado de trabalho nacional. 0 peso relativo de trabalhadores desprotegidos, sem cobertura pela Previdência Social, entre 2012 e 2019, nunca se mostrou inferior a $34,8 \%$ do total de ocupados (2016). Na RMSP, a proporção desses trabalhadores se mostrou relativamente menor que a média nacional ao longo de todo

Gráfico 3 - Taxa composta de subutilização da força de trabalho e Taxa de desocupação. Brasil e Região Metropolitana de São Paulo, 2012-2019

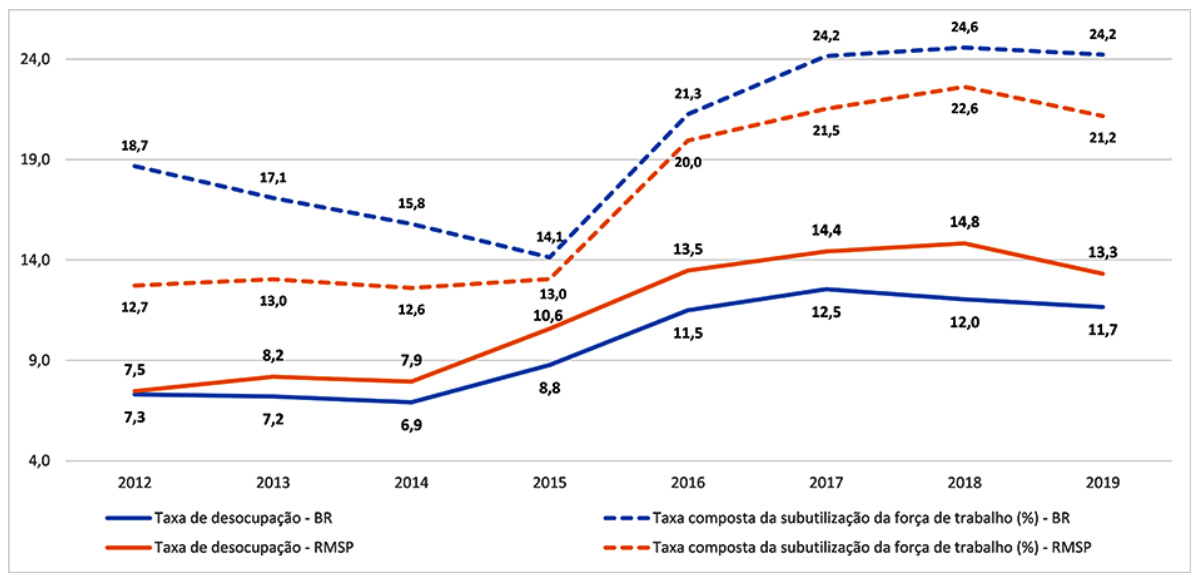

Fonte: IBGE, Pesquisa Nacional por Amostra de Domicílios Contínua. Elaboração própria. 
o período analisado. Ademais, as trajetórias dos indicadores de informalidade, pelo critério de contribuição, foram parecidas para o Brasil e para a RMSP. As diferenças observadas referem-se à intensidade dos movimentos ao longo do tempo.

A trajetória da informalidade na fase de desaceleração se mostrou mais intensa para a média do Brasil, permanecendo em queda até 2016. Na RMSP, o processo de redução da informalidade encerrou-se em 2014. Após 2015, a proporção de trabalhadores desprotegidos, na RMSP, ampliou-se de maneira expressiva (aumento de 6,3 pontos percentuais entre 2015 e 2018). Como pode ser observado, pelo Gráfico 4, no Brasil esse movimento foi relativamente menos intenso.

De modo geral, o que se pode observar é que a crise, seguida da lenta recuperação iniciada em 2017, foi marcada por uma elevação da subutilização da força de trabalho e da informalidade, tanto no Brasil quanto na RMSP. No entanto, em 2019, vê-se que o mercado de trabalho na RMSP respondeu relativamente melhor ao baixo e lento crescimento do PIB nesse ano, reduzindo, ao mesmo tempo, a desocupação, a subutilização e a informalidade. Já, para o Brasil como um todo, isso não se confirmou. Apesar de terem sido observadas reduções nas taxas de desocupação e de subutilização da força de trabalho entre 2018 e 2019, esse processo ocorreu pari passu a uma elevação da informalidade.

Do ponto de vista da evolução da ocupação, a RMSP apresenta algumas similaridades, mas, também, diferenças em relação à média do Brasil. Primeiramente, nota-se que o Brasil como um todo apresentou, durante a fase de desaceleração, uma elevação da participação da ocupação formal (com carteira de trabaIho assinada) no setor privado e do trabalho por conta própria vis-à-vis uma queda do peso

Gráfico 4 - Taxa de informalidade segundo critério de contribuição para a previdência.

Brasil e Região Metropolitana de São Paulo, 2012-2019

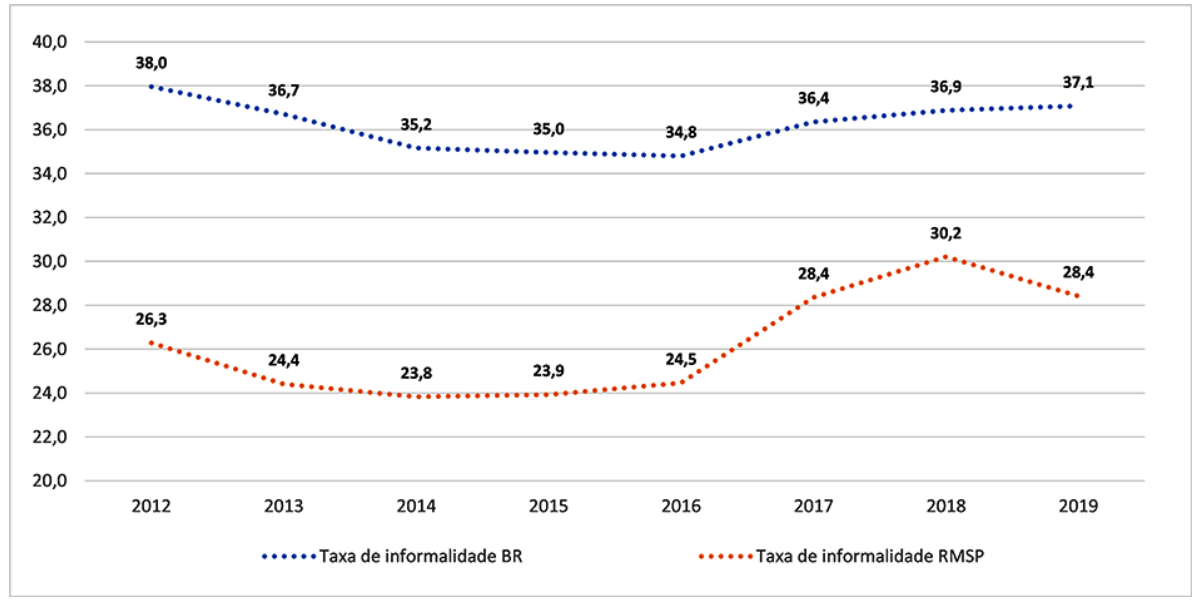

Fonte: IBGE, Pesquisa Nacional por Amostra de Domicílios Contínua. Elaboração própria. 
relativo da ocupação sem carteira no setor privado e nos serviços domésticos. Quanto à RMSP, nessa mesma fase (2012 a 2014), observa-se uma queda da participação do emprego no setor privado, especialmente no seu segmento formal com carteira de trabalho assinada. Também se observa, na RMSP, uma elevação do peso relativo do trabalho por conta própria e dos empregadores.

Outra diferença que chama a atenção são os distintos graus de formalidade existentes no setor privado. Enquanto os empregados com carteira representavam, em 2012, 38,4\% em média para o Brasil; na RMSP, eles representavam $52,7 \%$ do total de ocupados. Essa expressiva diferença se reduziu ao longo do período analisado, movimento que ganhou força a partir de 2015, com a crise econômica. Nem a lenta "recuperação" do após 2017 impediu a continuidade desse processo. A redução do peso relativo dos ocupados no setor privado com carteira deu-se de maneira muito mais intensa na RMSP, fazendo com que a diferença que era de 12,3 p.p., em 2012, caísse para 11,1 p.p. em 2019.

A crise também abriu espaço para que essa redução da formalização no setor privado viesse acompanhada por uma elevação do peso relativo da informalidade. No Brasil, a participação dos empregados sem carteira e por conta

Tabela 1 - Participação no total de ocupados segundo posição na ocupação.

Brasil e Região Metropolitana de São Paulo, 2012-2019

\begin{tabular}{|c|c|c|c|c|c|c|c|c|}
\hline \multirow{2}{*}{ Posição na ocupação } & \multicolumn{8}{|c|}{ Brasil } \\
\hline & 2012 & 2013 & 2014 & 2015 & 2016 & 2017 & 2018 & 2019 \\
\hline Empregado no setor privado com carteira de trabalho assinada & 38,4 & 39,1 & 39,3 & 38,7 & 37,7 & 36,3 & 35,6 & 35,8 \\
\hline Empregado no setor privado sem carteira de trabalho assinada & 12,5 & 12,0 & 11,5 & 11,1 & 11,5 & 12,1 & 12,5 & 12,7 \\
\hline Trabalhador doméstico com carteira de trabalho assinada & 2,1 & 2,0 & 2,1 & 2,2 & 2,2 & 2,0 & 1,9 & 1,8 \\
\hline Trabalhador doméstico sem carteira de trabalho assinada & 1,8 & 4,7 & 4,4 & 4,5 & 4,6 & 4,7 & 4,9 & 4,7 \\
\hline Ocupado no setor público (com e sem CLT, estatutário e militares) & 12,3 & 12,2 & 12,5 & 12,3 & 12,3 & 12,4 & 12,6 & 12,3 \\
\hline Empregador & 4,0 & 4,1 & 4,1 & 4,4 & 4,7 & 4,6 & 4,9 & 4,6 \\
\hline Conta própria & 22,8 & 22,9 & 23,2 & 24,2 & 24,7 & 25,3 & 25,4 & 25,8 \\
\hline Trabalhador familiar auxiliar & 3,1 & 3,0 & 2,9 & 2,7 & 2,4 & 2,4 & 2,3 & 2,2 \\
\hline \multirow[t]{3}{*}{ Total } & 100,0 & 100,0 & 100,0 & 100,0 & 100,0 & 100,0 & 100,0 & 100,0 \\
\hline & \multicolumn{8}{|c|}{ RMSP } \\
\hline & 2012 & 2013 & 2014 & 2015 & 2016 & 2017 & 2018 & 2019 \\
\hline Empregado no setor privado com carteira de trabalho assinada & 52,7 & 53,3 & 51,0 & 51,7 & 49,9 & 47,5 & 45,4 & 46,9 \\
\hline Empregado no setor privado sem carteira de trabalho assinada & 10,8 & 9,7 & 10,1 & 9,7 & 9,7 & 11,0 & 12,3 & 11,6 \\
\hline Trabalhador doméstico com carteira de trabalho assinada & 2,6 & 2,1 & 2,4 & 2,5 & 2,5 & 2,1 & 2,1 & 1,8 \\
\hline Trabalhador doméstico sem carteira de trabalho assinada & 3,5 & 3,6 & 3,8 & 3,8 & 3,8 & 4,2 & 4,3 & 3,8 \\
\hline Ocupado no setor público (com e sem CLT, estatutário e militares) & 8,2 & 8,6 & 9,1 & 8,2 & 7,6 & 7,7 & 7,8 & 8,0 \\
\hline Empregador & 4,2 & 4,5 & 4,7 & 5,3 & 5,7 & 5,5 & 5,4 & 4,9 \\
\hline Conta própria & 17,7 & 17,3 & 18,0 & 18,4 & 20,3 & 21,4 & 22,2 & 22,2 \\
\hline Trabalhador familiar auxiliar & 0,4 & 0,8 & 0,8 & 0,5 & 0,5 & 0,7 & 0,5 & 0,7 \\
\hline Total & 100,0 & 100,0 & 100,0 & 100,0 & 100,0 & 100,0 & 100,0 & 100,0 \\
\hline
\end{tabular}

Fonte: IBGE, Pesquisa Nacional por Amostra de Domicílios Contínua. Elaboração própria. 
própria ampliou-se 1,6 p.p. entre 2015 e 2019, enquanto, na RMSP, esse aumento foi de 1,9 p.p. para os trabalhadores sem carteira e 3,6 p.p. para aqueles ocupados por conta própria.

De modo geral, o que se nota é uma redução, no Brasil e na RMSP, do peso relativo do emprego no setor privado com carteira, incluindo os serviços domésticos, e uma elevação do emprego sem carteira e da ocupação por conta própria. Esse processo revela a fragilidade do mercado de trabalho nacional e dá sinais de que a RMSP tem se aproximado dessa condição. Em síntese, os dados por posição na ocupação indicam que a RMSP sofreu relativamente mais que a média nacional com o baixo dinamismo da atividade econômica.

Nos contextos de desaceleração, crise e lenta recuperação da atividade econômica, o setor da Indústria da Construção, por ser um grande empregador e por apresentar respostas relativamente mais intensas aos movimentos da atividade produtiva agregada, merece uma atenção especial. Primeiramente, destaca-se o fato de esta ser uma das atividades mais atingidas pela queda brusca da dinâmica econômica, tanto do ponto de vista do Valor Adicionado Bruto, quanto do emprego. Ademais, em um contexto de elevação da informalidade, pelo critério seja da contribuição para a previdência ou da ocupação via carteira de trabalho assinada, a Construção, que possui parcela expressiva da força de trabalho ocupada na informalidade, passou por um período de significativa retração, o que acabou por catalisar as perdas para a classe trabalhadora no âmbito do mercado de trabalho. É com um olhar mais atento para esse setor que as próximas seções trazem sua contribuição.

\section{Ocupação na construção e no subsetor da construção e incorporação de edifícios no brasil e na RMSP}

O processo de reestruturação produtiva, observado em âmbito mundial, intensifica-se no Brasil a partir dos anos 1990, com a abertura comercial e financeira e a desaceleração do ritmo de crescimento do PIB. Nesse contexto, há uma expansão expressiva do setor informal, e, dentro do formal, a criação de postos de trabalho concentra-se, sobretudo, no setor terciário, movimento que é acompanhado de perto pelo crescimento expressivo do desemprego. Em paralelo, ocorre um processo de deslocamento do emprego das grandes empresas industriais para estabelecimentos de menor porte por meio, principalmente, de terceirizações.

O caso da Construção não é diferente. A partir dos anos 1990, é possível verificar algumas transformações dos processos organizacionais, além de novas determinações no processo de acumulação de capital, especialmente, no subsetor de edificações. Segundo Villela (2008), os impactos da reestruturação produtiva na Indústria da Construção - subsetor de Edificação (ICCSE) podem ser observados a partir da implementação de diversos processos e programas:

1) Produção Enxuta (Lean Production) Construção Enxuta (Lean Construction); 2) Programas de Qualidade Total; 3) Racionalização dos Processos de Trabalho em Escritório; 4) Logística e Racionalização do Canteiro de Obras; 5) Horizontalização das Empresas; 6) Organizações 
em Constante Aprendizagem (Learning Organizations); 7) Gestão Participativa; 8) Políticas de Engajamento e Fixação dos Trabalhadores à Empresa; 9) Terceirizações (Outsourcing); e 10) Novas Estratégias Organizacionais. (Ibid., pp. 41-42)

Para esse autor, o conjunto de "Novas Tecnologias e Modos de Socialização, oriundos da Reestruturação Produtiva e implementados em maior ou menor intensidade na ICSSE, vem sendo denominado genericamente pelas empresas brasileiras Fast Construction - 'Construção Rápida'”. A lógica é concluir as obras em um menor prazo possível, com redução de custos e preços, garantindo maior padronização dos empreendimentos. Nessa estratégia, opta-se por uma seleção que mescla tecnologias construtivas tradicionais com outras mais avançadas, "tais como, Steel Deck, Tilt-up, Built to Suit, gestão de projetos do tipo Fast Track, Turn-Key, etc." (ibid., p. 42). No entanto, esses novos processos de produção, organização e gestão de projetos demandariam profissionais mais qualificados.

\section{Ainda de acordo com Villela,}

alguns exemplos que "agilizam" a Fast Construction são: 1) o Steel Deck, laje composta por aço galvanizado e que serve de forma para uma camada de concreto; 2) o Tilt-Up, que são paredes de concreto moldadas na horizontal, perto do local em que serão utilizadas e que, após a cura, são içadas e colocadas na fundação; 3) o Turn-key ("vire a chave", "chave na mão", "preço fechado", "custo global"", "porteira fechada"), que é um contrato que atribui à construtora a responsabilidade integral pela obra, desde o projeto, o fornecimento de materiais e equipamentos, a execução e até, em alguns casos, a operação e manutenção do empreendimento. (Ibid., pp. 42-43)
Nos anos 2000, a retomada do dinamismo da atividade econômica, a ampliação dos investimentos em infraestrutura econômica e social e a dinamização do mercado imobiliário, associadas à forte expansão da Construção, provocaram, além da intensificação da reestruturação produtiva, um aumento da internacionalização do setor, a partir da entrada de capitais estrangeiros e do aumento do grau de importação.

Segundo Villela (2008 apud Medeiros, 2003), a expansão de empreendimentos estrangeiros no País, especialmente nos ramos hoteleiro, de shoppings centers e de hipermercados, que já utilizavam os modelos de construção a partir de estruturas pré-fabricadas e obras rápidas, pressionou o mercado a se modernizar e ampliou a demanda por esse tipo de construção, principalmente, nas áreas metropolitanas brasileiras, como a RMSP. Associado às transformações já ocorridas no setor ao longo dos anos 1990, isso garantiu a continuidade do processo de reestruturação produtiva na construção de edificações.

A entrada de capitais (IDE), que já havia ocorrido de maneira mais expressiva em outros setores da economia brasileira nos anos 1990, acontece de maneira tardia no subsetor de Edificação e Incorporação, importante reduto do capital nacional até então. Como ressaltado por Mioto (2015), essa entrada de capitais ${ }^{6}$ ocorreu principalmente entre 2005 e 2009. Seu caráter era mais patrimonial e de ganho de mercado (market-seeking).

A entrada de IDE, em paralelo às mudanças recentes no sistema financeiro internacional, ampliou as formas de apropriação externa da renda da terra e da renda oriunda da Construção no País. Como demonstra Mioto (2015 apud Fix, 2011, p. 138), 
a estratégia das empresas perante a abertura de capitais foi ampliar a compra de terrenos na busca de manter, frente aos investidores, as possibilidades de efetivar o VGV (Valor Geral de Vendas) prometido no lançamento das ações, sendo o efeito principal desse processo o aumento generalizado do preço dos terrenos e a incorporação de novas áreas (periféricas, rurais, de fronteira, etc.) à dinâmica especulativa do setor imobiliário.

No entanto, um estudo realizado pela Ernest \& Young (2014), a respeito da produtividade na Construção, aponta para os desafios e as tendências no Brasil, evidenciando que houve uma expansão dos custos acima das receitas nas principais empresas de capital aberto do setor no início dos anos 2000. A partir da análise dos relatórios anuais de administração de sete das maiores incorporadoras e construtoras de capital aberto no Brasil, entre 2007 e 2011, o estudo mostra que o crescimento dos custos acima das receitas provocou impactos sobre as margens de lucro dessas empresas. Isso ocorreu, mesmo com a expansão dos lançamentos (em $\mathrm{m}^{2}$ ) e a elevação dos preços dos imóveis, ${ }^{7}$ o que havia garantido uma expansão média da receita líquida anual. Isso, segundo o estudo, aponta para a necessidade de aumento de produtividade nesse setor (ibid.).

Os resultados de uma pesquisa qualitativa com 74 executivos do setor da Construção no Brasil (empresas de diversos portes e dos ramos de construção pesada, construção industrial e de edifícios residenciais e industriais) demonstram que, segundo os entrevistados, "nos últimos dois anos, os esforços para ganhos de produtividade na Construção foram focados principalmente em melhorias de projetos e no aprimoramento do planejamento de empreendimentos" (ibid., p. 6).
Em suma, apesar de todas as transformações ressaltadas por Villela (2008) no desenvolvimento do processo de "Construção Rápida", o que parece de fato ter acontecido no Brasil dos últimos anos foi uma melhoria das técnicas, porém, com manutenção do uso de modelos construtivos tradicionais. Ademais, percebe-se que os ganhos de produtividade decorrem de mudanças nos processos de gestão e no desenvolvimento de projetos, ao invés daqueles que se originam na relação de produção no canteiro de obras. ${ }^{8}$ Esse movimento se evidencia pelo fato de o lucro do construtor não estar somente no canteiro de obras, mas, sobretudo, nos ganhos permitidos pela renda fundiária, como ressaltado por Pereira,

A valorização imobiliária do capital combinava a valorização pela exploração do trabalho e a capitalização da propriedade que, desde o último quartel do século XX, vem proporcionando maiores rendimentos com processo espoliativos. Processos que espoliam a sociedade inteira em função das mudanças regulatórias e das condições gerais urbanas, provocando elevação de preço da propriedade imobiliária, a seu modo, potencializam o uso do trabalho pelo capital compensando a sua baixa produtividade com renda capitalizada da terra acrescida, como parte da mais-valia. A generalização desses processos imobiliários de valorização e de capitalização serve para explicar a composição orgânica do capital na construção e permite entender (1) porque a construção deixa de encontrar na propriedade da terra um obstáculo e passa a instrumentalizar, cada vez mais, essa propriedade como uma vantagem para reprodução do capital e (2) porque a renda capitalizada não eleva os preços de mercado dos imóveis, mas é ela (a renda) que depende dessa valorização (do preço) no mercado para aumentar. (2018, pp. 65-66) 
Com a desaceleração, a crise e a lenta recuperação da atividade econômica e seus reflexos sobre o setor da Construção, a expectativa é que todos esses processos se intensifiquem ainda mais, ampliando terceirizações ${ }^{9}$ e aprofundando a precarização das relações trabalhistas no setor da construção, especialmente, no subsetor de Construção e Incorporação de Edifícios, tanto no Brasil quanto na RMSP. Destaca-se, ainda, a junção de uma conjuntura econômica e setorial desfavorável com a ampliação de medidas de flexibilização das relações trabalhistas, como a Reforma Trabalhista de 2017.

Os dados da Pnad-C anual para os anos de 2012 a 2019 permitem que se identifiquem a retração do setor da construção e os seus respectivos impactos para o mercado de trabalho no País e na RMSP. No ano de 2012, o setor da Construção representava $8,4 \%$ do total da ocupação no País, com um máximo de $8,8 \%$, em 2013. De 2014 em diante, a Construção perdeu importância relativa e chegou ao final de 2019 representando 7,2\% do total do emprego. Na RMSP, o movimento é parecido. Com o maior peso relativo em 2012 (7,1\% do total do emprego da região), o setor passou a diminuir sua importância, chegando a representar, em 2019, apenas 6,1\%. Em termos absolutos, de 2013 a 2019, o País perdeu 1 milhão e 275 mil postos de trabalho no setor, e, na RMSP, essa queda foi de 74.575 postos. A criação de 141 mil empregos no setor, em 2019 (8,7 mil na RMSP), não foi, nem de perto, capaz de compensar as perdas observadas nas fases de desaceleração e crise do setor e da economia brasileira como um todo.

A Construção na RMSP, em 2012, de acordo com os dados da Pnad-C anual, representava $9,4 \%$ do total emprego do setor no
Brasil. Essa participação aumentou para 9,72\% em 2019, decorrente das perdas relativamente maiores do Brasil quanto àquelas observadas na RMSP.

A Indústria da Construção como um todo pode ser dividida em três subsetores: 1) Construção e Incorporação de Edifícios; 2) Obras de Infraestrutura; e 3) Serviços Especializados para Construção. 0 primeiro representa aproximadamente $2 / 3$ do total do emprego do setor. Os serviços especializados são responsáveis por pouco menos de $1 / 3$ restante, e a menor participação refere-se às obras de infraestrutura. No entanto, é possível ressaltar alguns pontos quanto à evolução desses subsetores ao longo desse período.

Até 2014, o que se observa é uma ampliação da contribuição da Construção de Edifícios para o total do emprego, tanto na RMSP quanto no País. Destaca-se que, em 2013, esse subsetor atingiu seu ápice, chegando a representar $72,2 \%$ e $71,2 \%$ do total do emprego na Indústria da Construção no Brasil e na RMSP, respectivamente. No entanto, a partir de 2015, com a retração econômica e, também, do setor como um todo, tanto os serviços especializados ligados à Construção, quanto o subsetor de Obras de Infraestrutura, ampliaram seus pesos relativos no total da ocupação setorial (ver Gráfico 5).

Esse processo ocorreu por conta da queda expressiva do número de trabalhadores da Construção após 2014, no Brasil, e após 2013, na RMSP. As alterações em termos de participação devem-se aos ritmos de crescimento diferenciados entre os subsetores da Construção (ver Tabela 2).

$\mathrm{O}$ significativo aumento do peso relativo das Obras de Infraestrutura no total da ocupação da Construção deve-se a uma expansão do 
Gráfico 5 - Participação no total da população ocupada na Construção, segundo subsetores de atividades ligados ao setor, em (\%).

Brasil e Região Metropolitana de São Paulo, 2012-2019
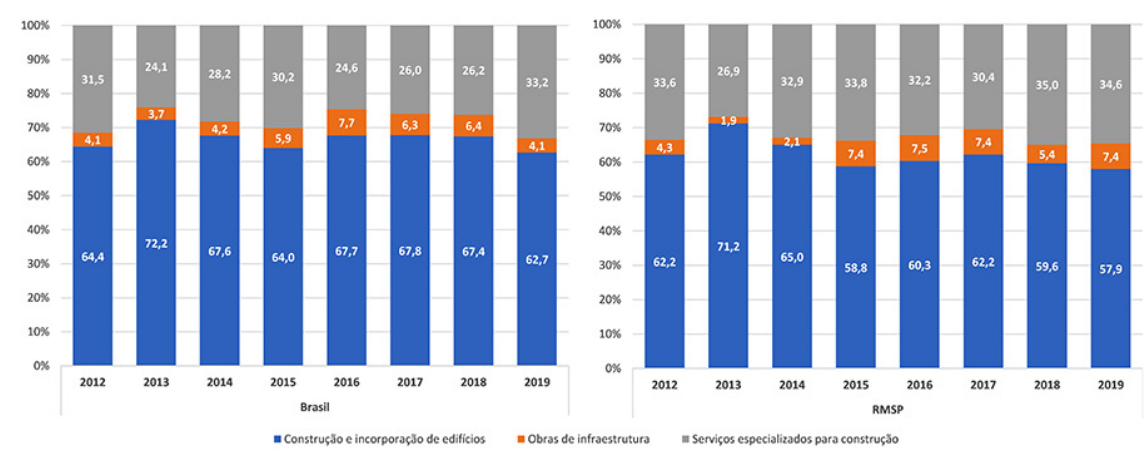

Fonte: IBGE, Pesquisa Nacional por Amostra de Domicílios Contínua. Elaboração própria.

emprego nesse subsetor, após 2014, no País e na RMSP, mas ainda representava apenas $4,1 \%$ das ocupações na Construção no Brasil e 7,4\% na RMSP, o que demonstra que, apesar de as Obras de Infraestrutura terem importante relação com os fundos públicos e com a melhoria das condições gerais da economia, elas têm baixa capacidade de absorção de mão de obra. O outro subsetor que elevou sua participação no total da ocupação da Construção, após 2016, no Brasil, foi o dos Serviços Especializados para Construção, que contribuem para a produção, mas não são a produção imediata. Porém, isso não se deu por conta de uma expansão nos postos de trabalho gerados pelo subsetor. $\mathrm{O}$ que ocorreu foi uma redução de postos de trabalho em ritmo mais lento que a queda observada para o subsetor de Construção e Incorporação de Edifícios no País. Já, na RMSP, os Serviços Especializados ampliam seu peso relativo entre 2016 e 2019 em decorrência de um crescimento de postos de trabalho, que se deu simultaneamente a uma queda nos postos de trabalho da Construção e Edificações de Edifícios.

Este último apresentou resultados expressivamente negativos no período analisado. Para se ter uma ideia, os postos de trabalho, nesse subsetor, foram reduzidos em aproximadamente 25\% no Brasil, de 2013 a 2019, e em $30 \%$ na RMSP. Tal processo está diretamente relacionado à contração do subsetor de Edificações ligado ao Programa Minha Casa Minha Vida, após $2013 .^{10}$ 
Tabela 2 - Evolução do total de ocupados nos subsetores da Construção (2012 = 100). Brasil e Região Metropolitana de São Paulo, 2012-2019

\begin{tabular}{|c|c|c|c|c|c|c|c|c|}
\hline \multirow{2}{*}{ Segmentos da Construção } & \multicolumn{8}{|c|}{ Brasil } \\
\hline & 2012 & 2013 & 2014 & 2015 & 2016 & 2017 & 2018 & 2019 \\
\hline Construção & 100 & 106 & 103 & 102 & 99 & 94 & 89 & 91 \\
\hline Construção e incorporação de edifícios & 100 & 119 & 108 & 101 & 104 & 99 & 93 & 94 \\
\hline Obras de infraestrutura & 100 & 96 & 105 & 146 & 186 & 143 & 139 & 162 \\
\hline Serviços especializados para construção & 100 & 81 & 93 & 97 & 77 & 77 & 74 & 75 \\
\hline \multirow{2}{*}{ Segmentos da Construção } & \multicolumn{8}{|c|}{ RMSP } \\
\hline & 2012 & 2013 & 2014 & 2015 & 2016 & 2017 & 2018 & 2019 \\
\hline Construção & 100 & 103 & 98 & 99 & 96 & 99 & 93 & 94 \\
\hline Construção e incorporação de edifícios & 100 & 118 & 102 & 93 & 93 & 99 & 89 & 88 \\
\hline Obras de infraestrutura & 100 & 47 & 48 & 172 & 170 & 172 & 118 & 165 \\
\hline Serviços especializados para construção & 100 & 83 & 96 & 99 & 92 & 89 & 97 & 97 \\
\hline
\end{tabular}

Fonte: IBGE, Pesquisa Nacional por Amostra de Domicílios Contínua. Elaboração própria.

As estruturas ocupacionais do setor da Construção no Brasil e na RMSP são basicamente as mesmas. A característica principal é o elevado peso relativo dos ocupados por conta própria, seguidos por empregados no setor privado com e sem careira, nessa ordem. Mais da metade dos ocupados da Construção na RMSP, em 2019, eram trabalhadores por conta própria. Nota-se, ainda, que a já elevada participação desses trabalhadores se ampliou entre 2012 e 2018, com algumas oscilações no percurso, especialmente na RMSP. Em 2019, os dados apontam para uma relativa alteração nesse processo.

A tendência mais geral para os empregados no setor privado foi de redução da participação no total do emprego da Construção, até 2015, tanto para aqueles com quanto sem carteira de trabalho assinada, um movimento que pode ser verificado no País como um todo e, também, na RMSP.
De 2015 a 2018, as trajetórias para os empregados do setor privado mostram-se distintas entre a RMSP e a média brasileira. No Brasil, houve uma elevação da participação dos empregados sem carteira e uma queda dos com carteira nesses anos (ampliação da informalidade). Já, na RMSP, de 2015 a 2018, o que se observa é exatamente o contrário, aumento da participação dos com carteira e queda dos sem carteira (queda da informalidade). Porém, de 2018 para 2019, as tendências inverteram-se, e o Brasil e a RMSP trocaram de papéis. Enquanto o primeiro vê um aumento da formalização no setor privado (queda da informalidade), na RMSP, o que se vê é um aumento da informalidade.

Para cumprir com o objetivo deste artigo, busca-se, a partir de agora, realizar uma breve imersão na estrutura ocupacional do subsetor que chegou a representar $2 / 3$ do total da ocupação do setor da Construção no 
Gráfico 6 - Participação no total da população ocupada na Construção, segundo posição na ocupação, em (\%).

Brasil e Região Metropolitana de São Paulo, 2012-2019

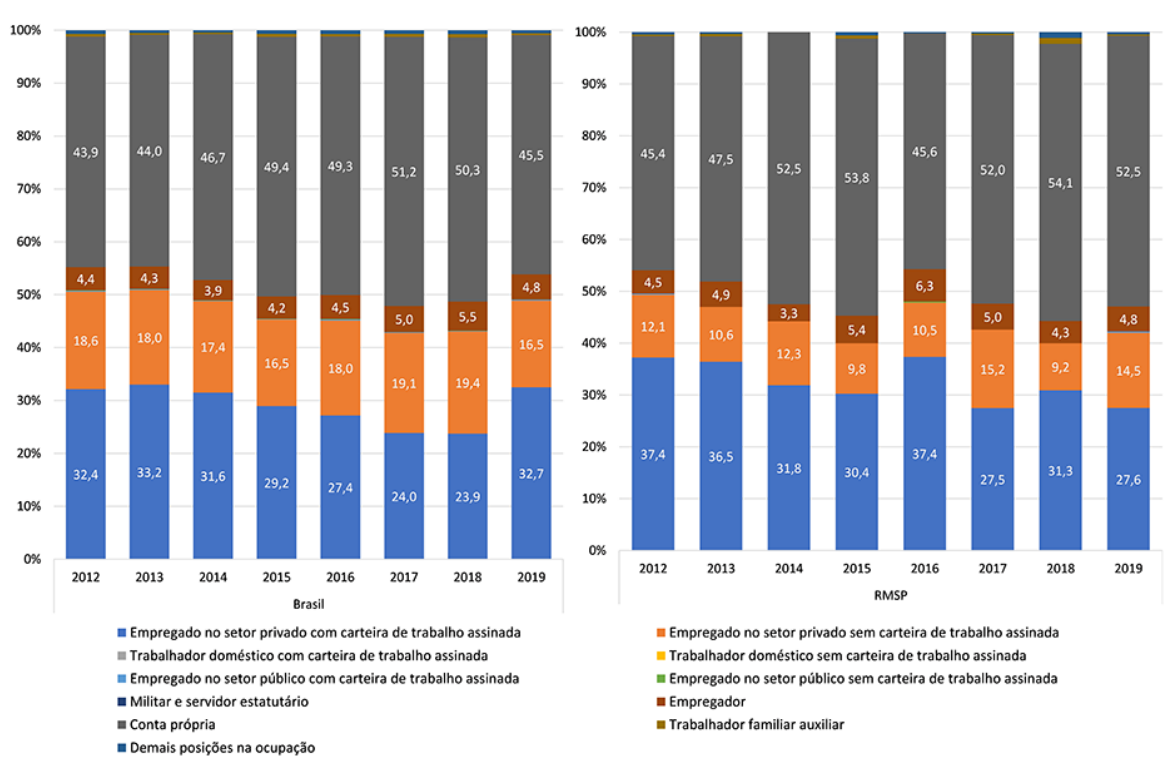

Fonte: IBGE, Pesquisa Nacional por Amostra de Domicílios Contínua. Elaboração própria.

País e que apresentou a maior retração entre todos os subsetores, a Construção e Incorporação de Edifícios. Essa análise se faz necessária para avaliar a evolução e as transformações que ocorreram na Indústria da Construção do País e da RMSP nesse contexto de baixo desempenho econômico.

A Construção e Edificação de Edifícios, em 2012, possuía mais da metade dos seus ocupados como empregados do setor privado. Dentre estes, a grande maioria possuía carteira de trabalho assinada. Essa caraterística era ainda mais marcante na RMSP, onde, do total de ocupados, $41,4 \%$ eram empregados com carteira assinada e apenas $13,6 \%$ eram sem carteira.

No entanto, de 2013 a 2018, tanto no Brasil, quanto na RMSP, observa-se um processo de redução do peso relativo do emprego privado com carteira e de aumento da participação daqueles sem carteira. Isso confirma um movimento mais geral de expansão da informalidade no setor da Construção, puxada pela Construção e Incorporação de Edifícios no 
País e na RMSP. Nesse subsetor, a participação de trabalhadores por conta própria era relativamente menor que a média da Construção como um todo. Mas, como subsetor predominante, sua evolução acabou por influenciar o processo mais geral de elevação do peso relativo dos trabalhadores por conta própria.

A única ressalva que deve ser feita diz respeito ao movimento observado entre 2018 e 2019. Na Construção e Incorporação de Edifícios do Brasil, há uma reversão do processo de expansão da informalidade, com aumento do peso relativo dos empregados com carteira e redução dos sem carteira. Já, na RMSP, o que se observa é um movimento que reforça o que se viu na região para o período anterior, ou seja, redução da participação no total da ocupação dos empregados com carteira e elevação dos sem carteira.

Em síntese, o processo de elevação da informalidade parece ter arrefecido no Brasil, entre 2018 e 2019, tanto na Construção, quanto em seu principal subsetor, a Construção e Incorporação de Edifícios. Porém, isso não se mostrou ser a realidade da RMSP, que, ao contrário, manteve uma trajetória de expansão do emprego sem carteira e de queda do emprego protegido pela CLT, o que acabou alterando suas participações relativas no sentido da ampliação da desproteção à classe trabalhadora.

Gráfico 7 - Participação no total da população ocupada no subsetor da Construção e Incorporação de Edifícios, segundo posição na ocupação, em (\%).

Brasil e Região Metropolitana de São Paulo, 2012-2019

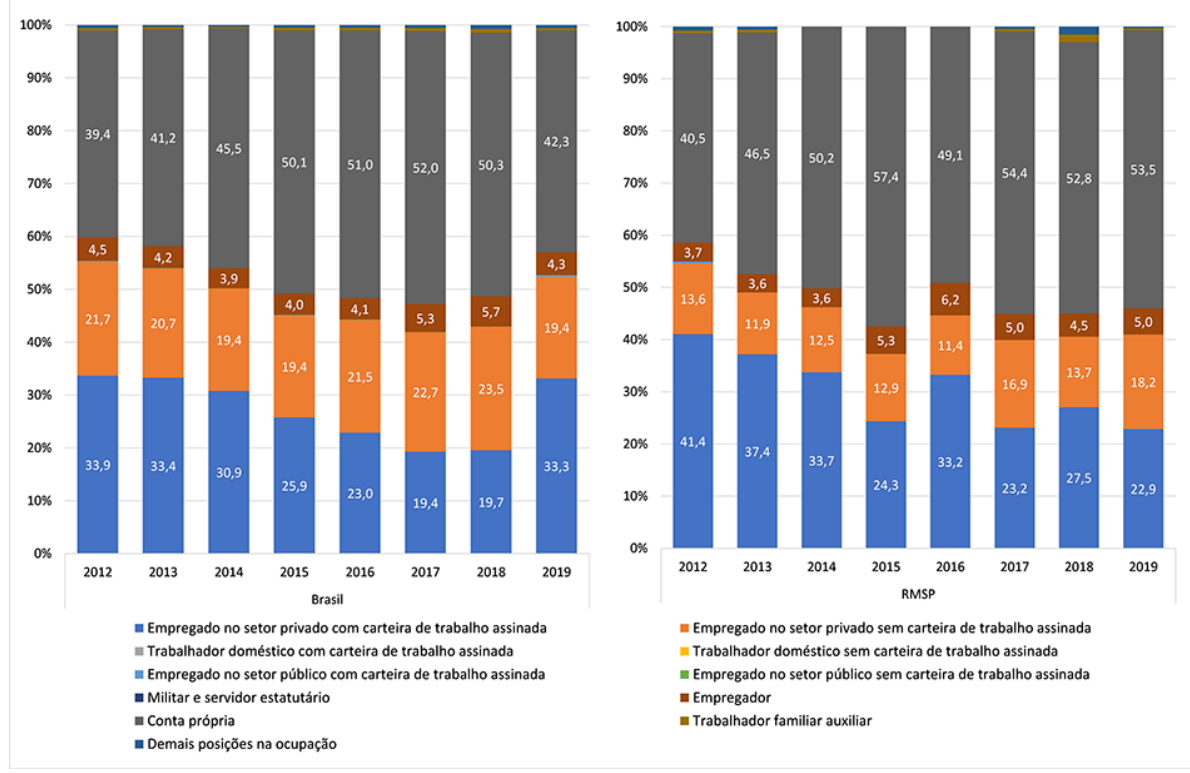

Fonte: IBGE, Pesquisa Nacional por Amostra de Domicílios Contínua. Elaboração própria. 
Esse processo de crescimento da informalidade, a que se tem chamado atenção, é confirmado pelos dados dos ocupados segundo critério da contribuição para a previdência. Como os trabalhadores por conta própria, maioria no subsetor da Construção e Incorporação de Edifícios, não possuem carteira de trabalho, pois não são contratados como empregados, uma análise da ocupação sob a ótica da contribuição para a previdência mostra-se fundamental para definir, não apenas a extensão da informalidade, como sua evolução.

Os dados revelam que, após 2013, ano em que se observa a menor taxa da série, a informalidade, segundo contribuição para a previdência, avançou no subsetor da Indústria da Construção, atingindo, em 2019, 69,7\% do total da ocupação do subsetor no Brasil e $64 \%$ na RMSP. Em termos comparativos, vale notar que a RMSP tem taxas de informalidade relativamente menores que a média nacional. Em outras palavras, a desproteção aos trabalhadores do setor tem sido a regra e tem se ampliado ao longo do tempo tanto para o Brasil quanto para a RMSP (ver Gráfico 8).

Apesar de possuir um mercado de trabalho, historicamente, mais bem-estruturado em termos de posição na ocupação, a RMSP ampliou o peso relativo dos empregados sem carteira e, por conta própria, o que se reflete nos dados de elevação da informalidade e, também, na participação dos ocupados na base da estrutura de renda. Em relação ao processo de precarização da força de trabaIho, destaca-se que o setor intensifica a exploração tanto da força de trabalho, quanto da produção de propriedades (redução das unidades, verticalização, adensamento, etc.). Como demonstrado por Oliveira (2016, p. 19), o setor da Construção "permanece com péssimas condições de trabalho, elevada incidência de acidentes e o trabalho análogo ao escravo continua sendo uma realidade em diversos canteiros".

Gráfico 8 - Participação no total da população ocupada no subsetor da Construção e Incorporação de Edifícios, segundo contribuição para a previdência, em (\%). Brasil e Região Metropolitana de São Paulo, 2012-2019

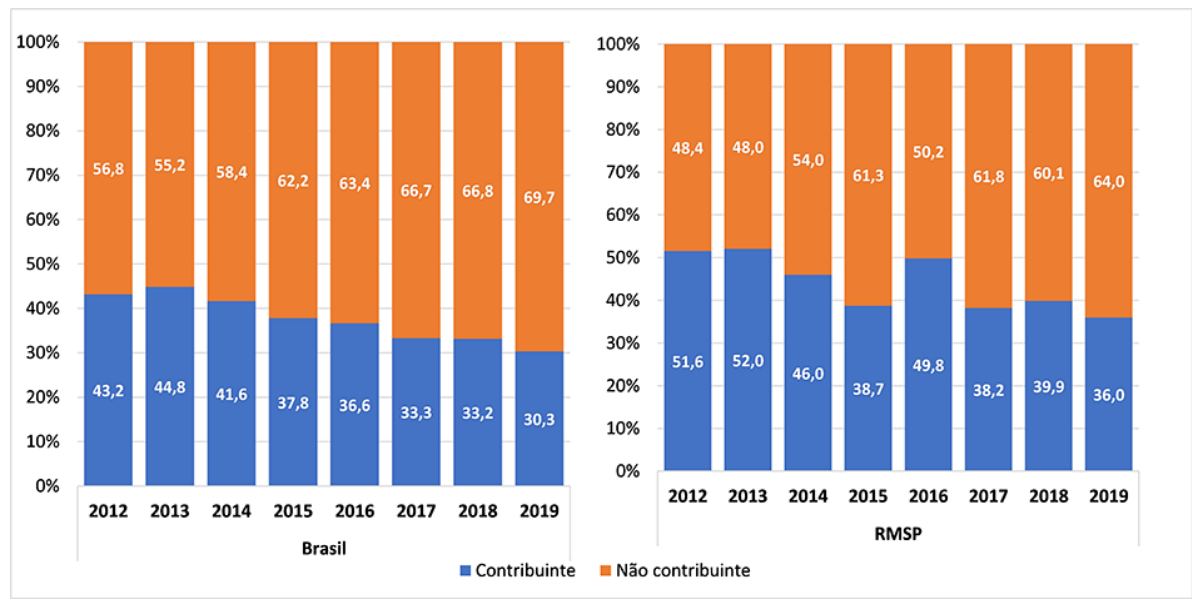

Fonte: IBGE, Pesquisa Nacional por Amostra de Domicílios Contínua. Elaboração própria. 
No que se refere à distribuição dos ocupados por faixa de salário-mínimo, a região inicia a série (2012) com 62,2\% dos ocupados na faixa de até 2 salários-mínimos e termina, em 2019, com 67,6\%. No Brasil, o processo de elevação da ocupação nas faixas de menor rendimento no subsetor da Construção e Incorporação de Edifícios foi mais lento. O País inicia com uma participação de $75,2 \%$ do total de ocupados nas faixas inferiores a 2 salários-mínimos e termina 2019 com $76 \%$.

É possível identificar dois subperíodos entre 2012 e 2019. Até 2014, via-se, no País e na RMSP, um aumento da participação de trabalhadores nas faixas intermediárias e mais elevadas, maiores que 2 salários-mínimos. No entanto, com a crise e a retração do setor, a participação dos trabalhadores de baixa renda amplia seu peso relativo, corroborando as características marcantes de um subsetor altamente informal e de baixa remuneração. Mesmo com a lenta recuperação, pós-2017, essas tendências permaneceram.

Após 2016, os dados da Pnad-C anual ${ }^{11}$ indicam um aumento, até 2018 , da participação dos trabalhadores por conta própria com Cadastro Nacional de Pessoa Jurídica (CNPJ) na Construção e Incorporação de Edifícios, uma proxy para as ocupações dos microempreendedores individuais (MEI), no Brasil e na RMSP. De 2018 para 2019, essa tendência permanece no caso do Brasil como um todo, mas se reverte na RMSP. Ainda assim, deve ficar claro que o peso relativo dos trabalhadores por conta própria na Construção com registro no CNPJ era, em média, de $8 \%$ dos conta própria para o Brasil e $10 \%$ para a RMSP.

Gráfico 9 - Participação no total da população ocupada no subsetor da Construção e Incorporação de Edifícios, segundo faixas de salários-mínimos, em (\%). Brasil e Região Metropolitana de São Paulo, 2012-2019

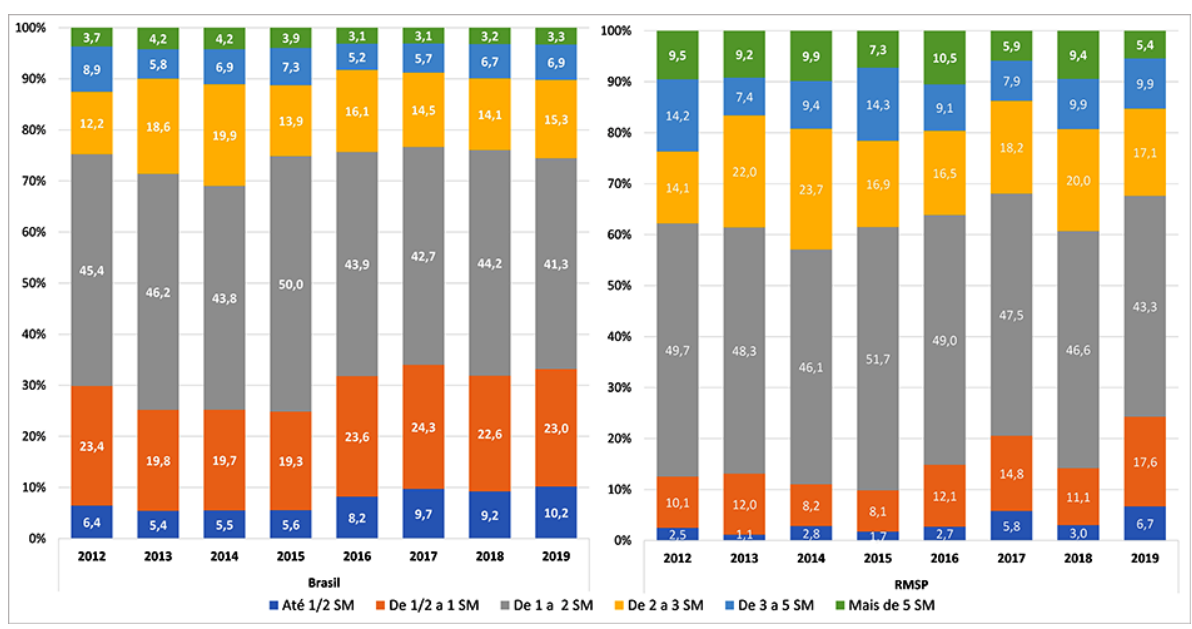

Fonte: IBGE, Pesquisa Nacional por Amostra de Domicílios Contínua. Elaboração própria. 


\section{A retração do emprego formal na construção de edifício ${ }^{12}$ no Brasil e na RMSP}

Parte do processo de elevação da informalidade na Indústria da Construção, observado anteriormente, está intimamente relacionada à retração do emprego formal no setor, especialmente no segmento da Construção de Edifícios, que, entre 2012 e 2018, segundo dados da Relação Anual de Informações Sociais (Rais), destruiu, aproximadamente, $493 \mathrm{mil}$ postos de trabalho no País (46,4 mil na RMSP). Essa queda expressiva de postos de trabalho, simplesmente, anula todo o crescimento do período de expansão vivenciado pelo setor, jogando-o de volta ao mesmo patamar de 2007 (ver Gráfico 10).
Enquanto nesse segmento se tem uma ampliação do estoque de trabalhadores no País como um todo, a RMSP já dava sinais de piora a partir de 2011. Ainda assim, o peso da RMSP no total do emprego formal nesse segmento do País, mensurado pela Rais, passou de $11 \%$, em 2012 , para $12,3 \%$, em 2018 . Isso se deve ao fato de a perda de postos de trabalho no Brasil ter sido relativamente maior que a verificada para a RMSP. Em 2019, observou-se um aumento da geração de empregos formais na Construção de Edifícios tanto no Brasil quanto na RMSP.

Seguindo uma tendência mais geral do mercado de trabalho, observa-se um aumento da rotatividade do emprego formal na Construção de Edifícios até 2015 no Brasil e, até 2014, na RMSP, quando a retração no setor se acentuou. No período de lenta

Gráfico 10 - Evolução do estoque em 31/12 do número de ocupados formais no segmento da Construção de Edifícios.

Brasil e Região Metropolitana de São Paulo, 2006-2019

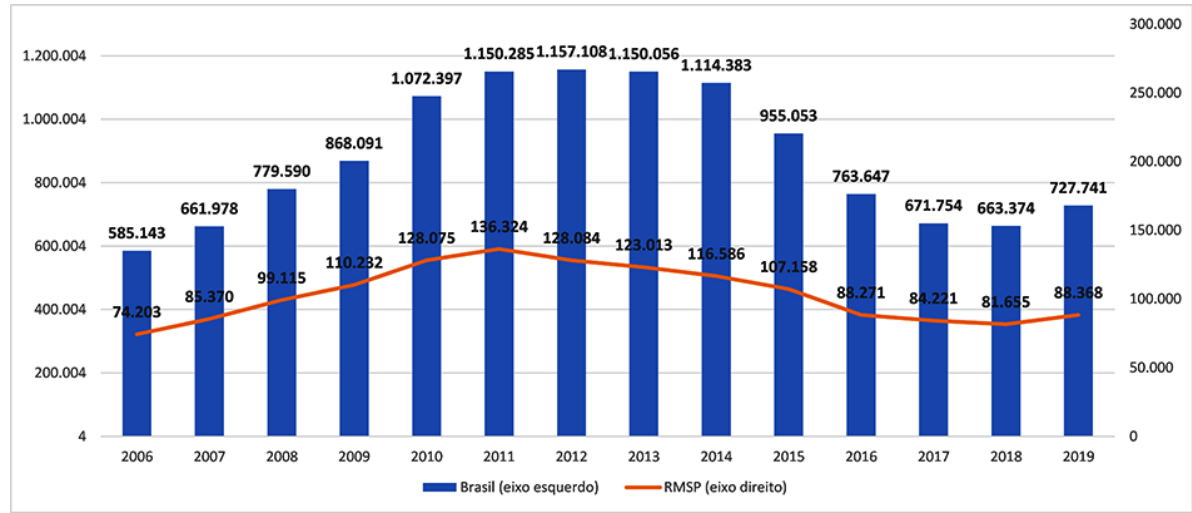

Fonte: Relação Anual de Informações Sociais (Rais). Elaboração própria. 
Gráfico 11 - Rotatividade do trabalho do emprego formal na Construção de Edifícios. Brasil e Região Metropolitana de São Paulo, 2006-2019

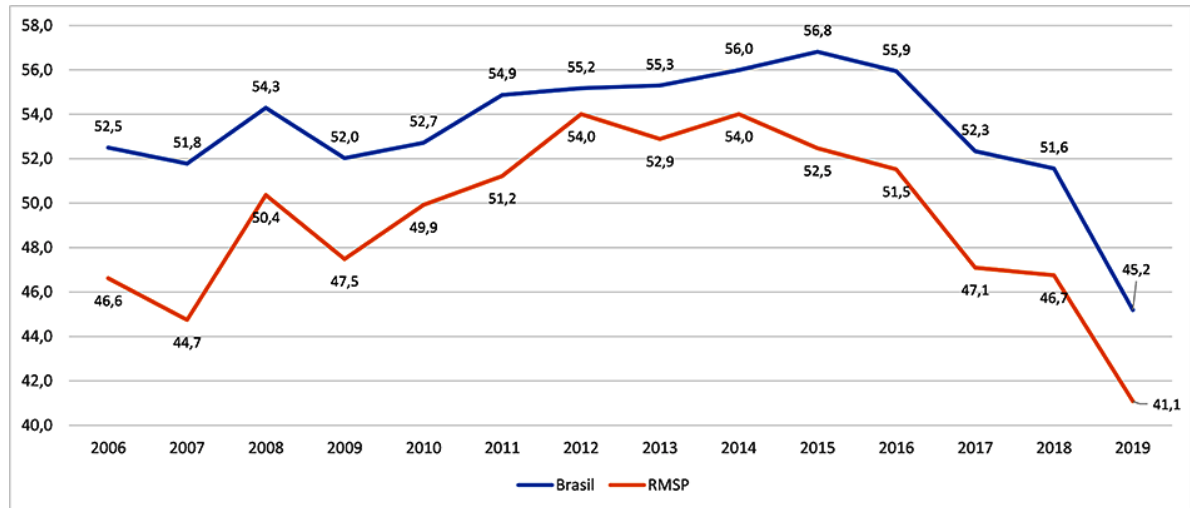

Fonte: Relação Anual de Informações Sociais (Rais). Elaboração própria.

Gráfico 12 - Evolução do saldo acumulado (admissões menos demissões) em termos absolutos (mil pessoas) na Construção de Edifícios segundo faixas de salário-mínimo.

Brasil, novembro de 2014 a dezembro de 2019

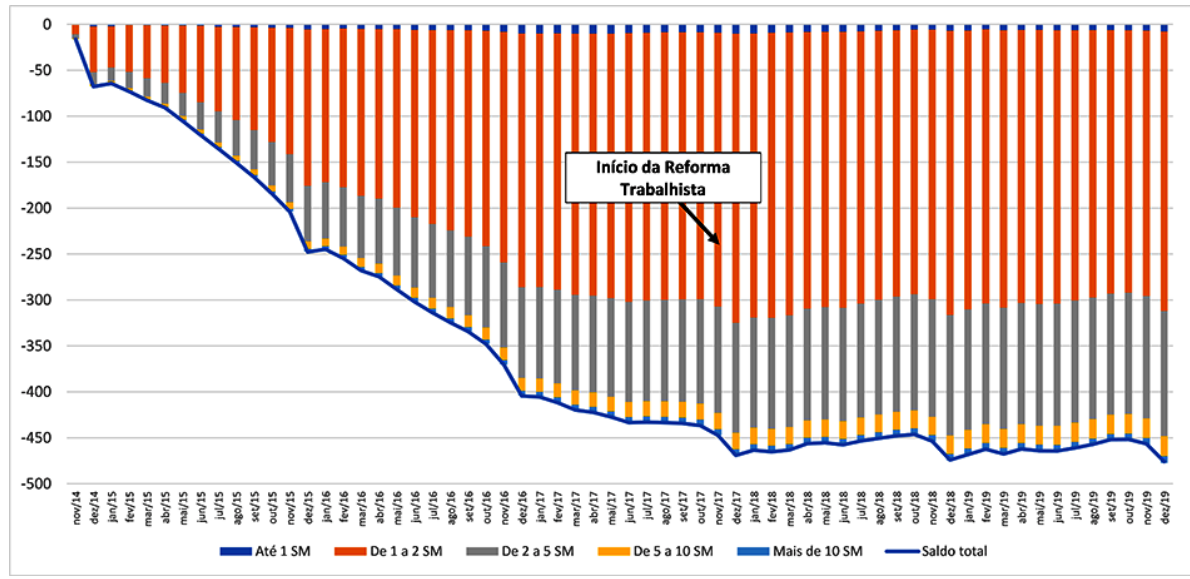

Fonte: antigo Ministério do Trabalho, Caged. Elaboração própria. 
retomada da atividade econômica, a partir de 2017, é possível verificar uma queda da rotatividade, reflexo do menor número de movimentações e não de uma melhoria no mercado de trabalho.

Essa forte retração no emprego formal na Construção e Incorporação de Edifícios também aparece sob o ponto de vista do fluxo de contratações e desligamentos mensurados pelo Cadastro Geral de Emprego e Desemprego (Caged). ${ }^{13}$ Para verificar o tamanho das perdas sofridas pelo setor, pode-se partir do ponto máximo do estoque de trabalhadores celetistas, que foi registrado em novembro de 2014. O objetivo é verificar o comportamento do fluxo acumulado de admissões e desligamentos de forma a encontrar algum sinal de recuperação do setor após 2017, ou mesmo se a reforma trabalhista implementada nesse ano e que entrou em vigor em novembro trouxe mudanças expressivas para os trabaIhadores do setor.

Os dados sugerem que a retração no setor foi intensa, a ponto de não conseguir criar empregos de forma a reduzir as perdas acumuladas ao longo da crise iniciada no final de 2014. Essas perdas acumuladas, em termos líquidos, desde dezembro de 2017, têm permanecido em torno de 500 mil postos de trabalho, confirmando que a Reforma Trabalhista teve pouco ou nenhum efeito para a criação de postos de trabalho no segmento de Construção de Edifícios.

Outro ponto que chama a atenção, para o total do País, é a concentração da destruição de postos de trabalho na faixa de até 2 salários-mínimos, indicando que aqueles que mais sofreram com a retração do setor foram os trabalhadores da base da distribuição de renda no País.

Gráfico 13 - Evolução do saldo acumulado (admissões menos demissões) em termos absolutos na Construção de Edifícios segundo faixas de salário-mínimo.

Região Metropolitana de São Paulo, novembro de 2014 a dezembro de 2019

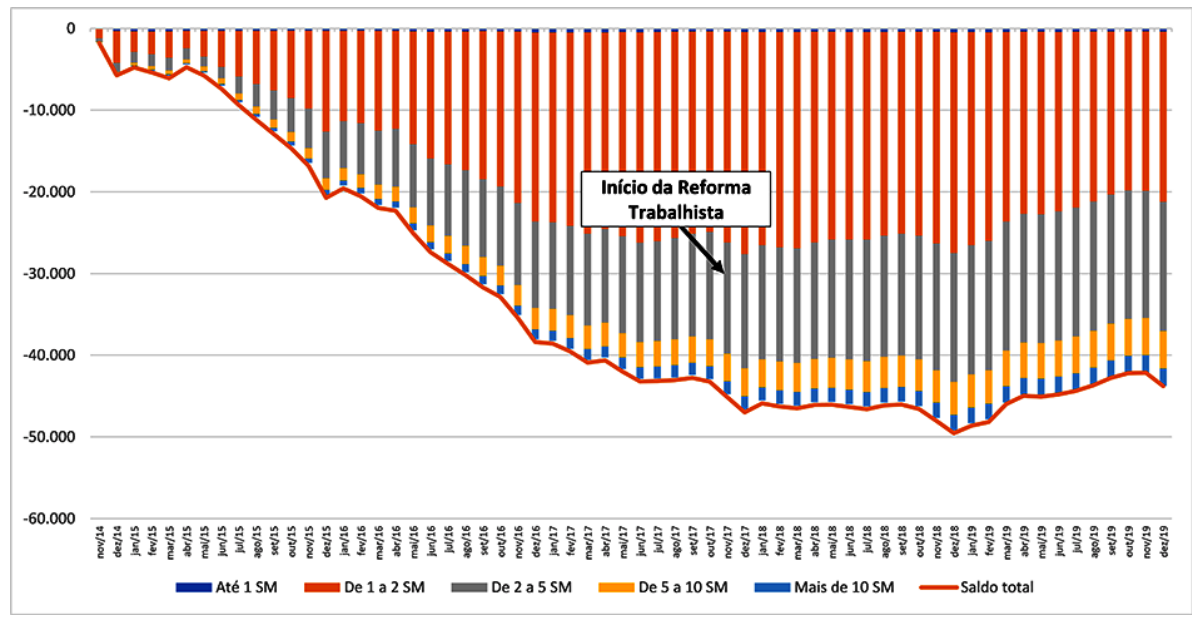

Fonte: antigo Ministério do Trabalho, Caged. Elaboração própria. 
Os dados para a RMSP apresentam um comportamento muito semelhante àquele observado para o total do País. No entanto, é necessário fazer uma ressalva. Desde janeiro de 2019, o segmento da Construção de Edifícios tem acumulado saldos positivos líquidos em termos de admissões e desligamentos. No entanto, o incremento de 5 mil postos de trabalho para esse segmento, no acumulado do ano de 2019, apresenta um ritmo de expansão que só permitiria uma recuperação das perdas acumuladas vistas durante a retração após 10 anos. Em outras palavras, apenas em 2029 a região retornaria ao patamar de novembro de 2014. Para além disso, destaca-se que essa recuperação tem se dado com a criação de postos de trabalho na faixa de 1 a 2 salários-mínimos, o que reforça a característica de uma estrutura ocupacional marcada pela baixa remuneração.

Os dados do Caged apontam ainda que, no acumulado entre novembro de 2017 (início da vigência da Reforma) e dezembro de 2019, o saldo entre contratações e desligamentos na Construção de Edifícios ficou em -2,8 mil postos de trabalho na RMSP. Esse foi o resultado de 3,2 mil desligamentos de trabalhadores com contratos-padrão e a contratação de pouco mais de 400 trabalhadores por meio das novas formas de contratos trabalhistas previstos na Reforma (intermitente e/ou por regime parcial). Isso demostra que, diante do fluxo de contratações no setor, essas novas formas possuem inexpressiva representatividade nessa região metropolitana.

\section{0: Ruptura e impactos da pandemia no mercado de trabalho - o que acontece com a construção?}

A crise sanitária da Covid-19, impôs aos governos, em escala global, a necessidade da adoção de medidas de distanciamento e isolamento sociais. Tais ações provocaram uma crise de oferta, decorrente da impossibilidade de trabalhadores aglomerarem-se em seus postos de trabalho ou nos transportes públicos, e uma crise de demanda, oriunda da redução e/ou paralisação das atividades produtivas, o que gerou perdas para a classe trabalhadora em termos de emprego e renda, inclusive no setor da Construção. O resultado é um cenário de crise sanitária, econômica e, também, social. Ao analisar os dados da variação do PIB trimestral de 2020, em comparação ao mesmo período de 2019, observa-se uma forte retração da atividade econômica no segundo e terceiro trimestres. Seguindo a dinâmica da FBKF, o setor da Construção já apresentava queda de sua atividade desde o começo de 2020. Não sendo possível atribuir seu desempenho econômico à pandemia, no primeiro trimestre, a queda do Valor Adicionado Bruto da Construção já se mostrava mais expressivo que a média dos demais setores. Destaca-se que esse movimento se manteve no segundo e terceiro trimestres de 2020.

Tal cenário exigiu um conjunto de ações por parte dos governos de todo o mundo para salvar e preservar os empregos e a massa 
de renda da classe trabalhadora. No Brasil, a pressão popular, de diversos setores da sociedade, levou o governo a tomar medidas nessa direção, a partir da criação de dois programas emergenciais com públicos-alvo distintos: a) trabalhadores formais - Programa Emergencial de Manutenção do Emprego e da Renda; e b) trabalhadores informais, microempreendedores individuais (MEI), desempregados e beneficiários do Bolsa Família (PBF) - Auxílio Emergencial.

Em relação ao setor da Construção, os dados da Pnad-C, do IBGE, apontam que o setor já vinha apresentando uma retração da ocupação no início de 2020. Com a pandemia, esse movimento se intensifica fortemente no segundo e terceiro trimestres de 2020, quando comparados ao mesmo período de 2019. Esse movimento é mantido no último trimestre de 2020 (Brasil e RMSP). No primeiro trimestre de 2021, a economia brasileira apresentou relativa recuperação em relação ao mesmo trimestre do ano anterior. No entanto, a Indústria da Construção apresentou uma retração de $-0,9 \%$.

Os segmentos da Construção e Incorporação de Edifícios e de Serviços Especializados são os que apresentaram as maiores perdas de postos de trabalho. 0 único segmento que ampliou o número de postos de trabalho, nos dois primeiros trimestres de 2020, é o de Obras de Infraestrutura da RMSP. No terceiro trimestre de 2020, há uma redução de postos de trabaIho nesse mesmo segmento, com ligeira recuperação no último trimestre de 2020, com nova queda em 2021 (Tabela 3). Vale ressaltar,

Tabela 3 - Evolução dos indicadores de atividade econômica e mercado de trabalho na Construção (variação \% em relação ao mesmo semestre do ano anterior).

Brasil e Região Metropolitana de São Paulo, 2020

\begin{tabular}{|c|c|c|c|c|c|c|c|c|c|c|c|}
\hline \multirow{2}{*}{ Indicador } & \multirow{2}{*}{ Setor } & \multicolumn{5}{|c|}{ Brasil } & \multicolumn{5}{|c|}{ RMSP } \\
\hline & & 2020.01 & 2020.02 & 2020.03 & 2020.04 & 2021.01 & 2020.01 & 2020.02 & 2020.03 & 2020.04 & 2021.01 \\
\hline \multirow{4}{*}{$\begin{array}{l}\text { Número } \\
\text { de } \\
\text { ocupados }\end{array}$} & Construção de ediifícios & $-5,8$ & $-23,8$ & $-15,5$ & $-11,1$ & $-2,4$ & $-11,5$ & $-28,0$ & $-13,0$ & $-7,6$ & $-0,7$ \\
\hline & Construção de obras de infraestrutura & $-0,8$ & $-5,1$ & $-16,7$ & $-4,9$ & $-4,4$ & 33,5 & 58,3 & $-5,4$ & 3,4 & $-2,7$ \\
\hline & Serviços especializados para construção & 7,5 & $-11,4$ & $-19,2$ & $-15,1$ & $-13,7$ & $-1,9$ & $-24,0$ & $-24,0$ & $-13,2$ & $-1,4$ \\
\hline & Total & $-2,1$ & $-19,4$ & $-16,6$ & $-11,8$ & $-5,7$ & $-6,2$ & $-22,7$ & $-16,9$ & $-8,9$ & $-1,1$ \\
\hline \multirow{4}{*}{$\begin{array}{l}\text { Massa de } \\
\text { rendimentos } \\
\text { reais efetivos } \\
\text { de todos os } \\
\text { trabalhos }\end{array}$} & Construção de ediifícios & 2,2 & $-20,5$ & $-17,0$ & $-18,6$ & $-15,4$ & 1,4 & $-41,9$ & $-31,9$ & $-26,4$ & $-33,8$ \\
\hline & Construção de obras de infraestrutura & $-7,0$ & $-4,4$ & $-24,7$ & $-5,6$ & $-11,6$ & $-20,7$ & 50,9 & $-44,6$ & $-53,7$ & $-29,7$ \\
\hline & Serviços especializados para construção & 7,7 & $-20,3$ & $-32,7$ & $-18,6$ & $-23,3$ & 8,0 & $-18,2$ & $-38,1$ & $-16,1$ & $-42,4$ \\
\hline & Total & 2,7 & $-18,8$ & $-22,2$ & $-17,3$ & $-17,3$ & 1,0 & $-25,6$ & $-35,6$ & $-26,1$ & $-36,8$ \\
\hline \multicolumn{2}{|l|}{ Construção } & $-1,6$ & $-13,6$ & $-7,9$ & $-4,8$ & $-0,9$ & - & - & - & - & - \\
\hline \multicolumn{2}{|c|}{ Formação bruta de capital fixo } & 6,0 & $-13,9-$ & $-7,8$ & 13,5 & 17,0 & - & - & - & - & - \\
\hline \multicolumn{2}{|c|}{ PIB a preços de mercado } & $-0,3$ & 10,9 & $-3,9$ & $-1,1$ & 1,0 & - & - & - & - & - \\
\hline
\end{tabular}

Fonte: IBGE, Contas Nacionais Trimestrais e Pnad-C, trimestral. Elaboração própria. 
nesse caso, que o segmento da Construção e Incorporação de Edifícios respondia por 62,7\% da ocupação do setor no Brasil e 57,9\% na RMSP (Gráfico 5) e que este é composto, em sua maioria, por trabalhadores por conta própria (Gráfico 7). Isso reforça a tendência devastadora da crise provocada pela pandemia sobre o mercado de trabalho como um todo. De 1 milhão de ocupações perdidas entre o primeiro e segundo trimestre de 2020 no Brasil, 783 mil foram na Construção e Incorporação de Edifícios; na RMSP, dos 90 mil postos de trabalho fechados, mais de 66 mil foram nesse segmento da Construção.

Em relação à massa real de renda de todos os trabalhos, destaca-se que ela vinha crescendo no primeiro trimestre de 2020, quando foi fortemente impactada, em todos os subsetores, a partir do segundo trimestre de 2020 (com exceção das Obras de Infraestrutura na RMSP). A massa de renda não se recupera, nem no Brasil nem na RMR, no setor da Construção Civil até o primeiro trimestre de 2021. Considerando que os ocupados na Construção e Incorporação de Edifícios, em sua maioria, são trabalhadores por conta própria (Gráfico 7), pode-se inferir que sua perda de renda, em tese, foi amortecida pelo auxílio emergencial. No entanto, considerando o baixo valor médio do auxílio, pouco superior aos $\mathrm{R} \$ 600,00$ de referência do programa, bem como sua não continuidade no primeiro trimestre de 2021 e seu retorno, após abril deste ano, com valores inferiores à média do programa original, é razoável pensar que tal política não foi suficiente para cobrir as perdas desses trabalhadores em termos de renda.

\section{Considerações finais}

A retração do mercado de trabalho no setor da Construção foi significativa a partir do processo de desaceleração da atividade em 2012. A crise econômica, política e institucional de 2015-2016 acentuou esse movimento de precarização do trabalho, que não foi revertido pela Reforma Trabalhista ou pela lenta recuperação econômica iniciada em 2017, que impulsionaram, sobretudo, a criação de postos de trabalho de baixa remuneração. A pandemia impactou de maneira expressiva a sociedade brasileira, evidenciando a necessidade de meIhorias nas relações e condições de trabalho, em especial, na Construção.

A Construção e Incorporação de Edifícios é o subsetor de maior peso relativo na ocupação dentro da Construção. Mesmo apresentando melhores condições de trabalho na RMSP em comparação com a média nacional, foi possível observar que, no período de retração, houve uma forte queda do emprego formal (retornando a patamares de 2007), um aumento do trabalho por conta própria, o crescimento do emprego no setor privado sem carteira, a ampliação da informalidade por contribuição para a previdência e da ocupação de baixa remuneração (até 2 salários-mínimos). A rotatividade do trabalho aumentou até 2014 na RMSP e cai, na sequência, como reflexo não de uma melhora no mercado de trabalho, mas, sim, do menor número de movimentações.

A Construção e, mais especificamente, a Construção de Edifícios têm um importante potencial de geração de emprego e renda. Em um contexto de retomada da atividade 
econômica, esse setor poderia ter importante papel no escopo de uma política anticíclica de redução do histórico déficit habitacional e de acesso à infraestrutura social no País. Todavia, seu crescimento exige pelo menos duas reflexões a respeito: 1) da definição de qual o modelo de política habitacional que se pretende implementar a partir de uma visão crítica ao PMCMV; e 2) de como avançar para melhorar as relações e condições de trabalho no setor, uma vez confirmado que propostas de flexibilização das relações trabalhistas, tais como a Reforma Trabalhista de 2017, não são o caminho.
A pandemia, por sua vez, intensificou o conflito social e os desafios para o mercado de trabalho nacional, que já se mostravam significativos desde a crise de 2015-2016. As políticas sanitárias, econômicas e sociais tardias, ineficientes e de fôlego curto, implementadas em caráter emergencial, reafirmam esse processo. Mais que isso, a pandemia deixou evidente a significativa desproteção e a precária inserção ocupacional de grande parte da força de trabaIho brasileira, escancarando a necessidade de políticas sociais estruturais mais abrangentes e de longo prazo.

\section{[1] https://orcid.org/0000-0002-0523-4231}

Universidade Federal do Rio Grande do Norte, Centro de Ciências Sociais Aplicadas, curso de Ciências Econômicas, Departamento de Economia. Natal, RN/Brasil.

juliana.bacelar@ufrn.br

\section{[II] https://orcid.org/0000-0002-0292-5651}

Universidade Federal do Rio Grande do Norte, Centro de Ciências Sociais Aplicadas, curso de Ciências Econômicas, Departamento de Economia, Programa de Pós-Graduação em Economia. Natal, RN/Brasil.

cassiano.trovao@ufrn.br

\section{Notas}

(1) A Indústria da Construção é composta pelas divisões 41 (construção de edifícios), 42 (obras de infraestrutura) e 43 (serviços especializados para construção) da Classificação Nacional de Atividades Econômicas (Cnae) 2.0.

(2) Ver Trovão e Araújo (2018 e 2020).

(3) Esses fenômenos eram pesquisados, no Brasil, apenas na Pesquisa de Emprego e Desemprego do Departamento Intersindical de Estatística e Estudos Socioeconômicos (Dieese) e na Pesquisa Mensal de Emprego (PME) encerrada em março de 2016, cujas abrangências se restringiam ao mercado de trabalho urbano em regiões metropolitanas específicas. 
(4) Subutilizados = desocupados + subocupados + desalentados + restante da força de trabalho potencial.

(5) Força de trabalho ampliada = força de trabalho + força de trabalho potencial.

(6) Em relação à entrada de capitais, segundo Mioto (2015, p. 97 apud Bertasso, 2012), "no caso dos investimentos produtivos, as formas mais relevantes são das Sociedades de Propósito Específico - SPEs, onde as empresas estrangeiras buscam parcerias nacionais para executar as obras. No caso patrimonial estão a participação acionária (Oferta inicial de ações - IPO), private equity para empresas maiores e venture capital para as médias e menores".

(7) Ressalta, contudo, que o aumento de preço dos terrenos, pelo aumento da demanda, gera também aumento da renda fundiária, e esse aumento, por sua vez, empurra a produção intensiva para as novas áreas (periféricas, rurais, de fronteira, etc.) ou para onde predomina a construção horizontal. Além disso, o aumento de preço dos terrenos também pode ser decorrente de maior quantidade de valor disponível que circula, como no caso das empresas construtoras de capital aberto. Segundo Sanfelici (2016, p. 19), o mercado de capitais passou a alicerçar suas expectativas de rentabilidade futura das empresas de capital aberto do setor imobiliário "na dimensão do banco de terrenos que as empresas possuíam". Esses dois movimentos demonstram que, ao menos em parte, o aumento do "custo da produção" também decorreu do aumento do preço dos terrenos e, consequentemente, da renda fundiária (propriedade).

(8) Ressalta-se, ainda, que essas transformações na gestão do canteiro só se difundiram para regiões mais periféricas com a entrada de grandes incorporadoras nos mercados locais, sobretudo a partir de meados da década de 2000.

(9) A Pnad-C não traz, em seu questionário, qualquer pergunta a respeito da característica do contratante, de forma que seja possível identificar se se trata de uma empresa de intermediação de mão de obra.

(10) Ver Mioto (2015) e Fiesp (2019).

(11) A pesquisa sobre posse de registro no CNPJ para trabalhadores por conta própria e empregadores passou a ser realizada a partir do último trimestre de 2015.

(12) Diferentemente da Pnad-C que utiliza a Classificação Nacional de Atividades Econômicas Domiciliar (CNAEDom 2.0), que é mais agregada e nos permite olhar apenas para o conjunto da Construção e Incorporação de Edifícios, as bases da Rais e Caged utilizam a Cnae completa, que pode ser desagregada até 7 dígitos e nos permite olhar, a partir de 2006, quando é disponibilizada a Cnae 2.0, os dados de emprego da Construção de Edifícios.

(13) O Caged capta informações dos contratos de trabalho regidos pela CLT em termos de fluxo. 


\section{Referências}

ARAÚJO, J. B.; PRADO, M. A. P. (2015). “Qualificação profissional das mulheres na Indústria da Construção Civil da RMSP entre 2009 e 2013”. In: ÁVILA, M. B.; FERREIRA, V.; ARANTES, R. (orgs.). Desenvolvimento, trabalho e autonomia econômica na perspectiva das mulheres brasileiras. Recife, SOS Corpo, v. 1, pp. 271-309.

BERTASSO, B. (2012). Edificações: impasses da modernização no ciclo de crescimento dos anos 2000. Tese de doutorado. Campinas, Universidade Estadual de Campinas.

DEDECCA, C. S.; BALTAR, P. E. A. (1997). Mercado de trabalho e informalidade nos anos 90. Estudos Econômicos. São Paulo, v. 27, no especial, pp. 65-84.

DIEESE (2011). Estudo setorial da construção. Estudos e Pesquisas, n. 56, abril.

(2014). Rotatividade setorial: dados e diretrizes para a ação sindical. São Paulo, Dieese.

(2020). A construção civil e os trabalhadores: panorama dos anos recentes. Estudos e Pesquisas, n. 95, julho.

ERNEST \& YOUNG (2014). Estudo sobre produtividade na Construção Civil: desafios e tendências no Brasil. Disponível em: < http://www.ey.com/Publication/vwLUAssets/EY_Estudo_Produtividade_ na_Construcao_Civil/\$FILE/Estudo_Real_Estate.pdf>. Acesso em: 15 maio 2015.

FIESP (2019). Dez anos do PMCMV - Evolução das contratações e investimentos. Disponível em: https://www.fiesp.com.br/observatoriodaconstrucao/noticias/evolucao-das-contratacoes -e-investimentos-do-pmcmv/. Acesso em: 30 mar 2021.

FIX, M. de A. B. (2011). Financeirização e transformações recentes no circuito imobiliário no Brasil. Tese de doutorado. Campinas, Universidade Estadual de Campinas.

LENCIONI, S. (2014). Reestruturação imobiliária: uma análise dos processos de concentração e centralização do capital no setor imobiliário. Eure, v. 40, n. 120, pp. 29-47.

MEDEIROS, H. (2003). Quebre recordes, seja fast. Téchne, São Paulo, n. 79, pp. 40-47.

MIOTO, B. T. (2015). As políticas habitacionais no subdesenvolvimento: os casos do Brasil, Colômbia, México e Venezuela (1980/2013). Tese de doutorado. Campinas, Universidade Estadual de Campinas.

MIOTO, B. T.; CASTRO, C. M. P. de; SÍGOLO, L. M. (2019). Expansão e desaceleração do mercado privado formal de moradia a partir dos anos 2000 na Região Metropolitana de São Paulo. Cadernos Metrópole. São Paulo, v. 21, n. 44, pp. 253-280.

OLIVEIRA, M. R. de (2016). Mercado de trabalho na Construção Civil: o subsetor da construção de edifícios durante a retomada do financiamento habitacional nos anos 2000. Dissertação de mestrado. Campinas, Universidade Estadual de Campinas.

ORAIR, R. O. (2016). Investimento público no Brasil: trajetória e relações com o regime fiscal. Brasília, Ipea (Texto para discussão n. 2215).

PAC/MPOG (2014). 11 Balanço Completo do PAC 2 - 4 anos (2011-2014). Disponível em: <http:// www.pac.gov.br/sobre-o-pac/publicacoesnacionais>. Acesso em: jan 2015.

PENHA FILHO, C. A. (2020). Estratégias e dinâmica de acumulação das incorporadoras listadas (2010/2018). Tese de doutorado. Campinas, Universidade Estadual de Campinas. 
PEREIRA, P. C. X. (2018). "Para a discussão do valor e do preço na produção imobiliária”. In: PEREIRA, P. C. X. (org.). Imediato, global e total na produção do espaço: a financeirização da cidade de São Paulo no século XXI. São Paulo, FAU-USP.

PINTO, E. C. et al. (2017). A Guerra de todos contra todos: a crise brasileira. Texto para discussão 006 - IE/UFRJ. Rio de Janeiro, IE/UFRJ, fev.

ROSSI, P.; MELLO, G. (2017). Choque recessivo e a maior crise da história: a economia brasileira em marcha à ré. Centro de Estudos de Conjuntura e Política Econômica - IE/Unicamp, Nota do Cecon, n. 1, abril.

SANFELICI, D. (2016). Centralização do capital no setor imobiliário e reconfiguração das metrópoles. Mercator, v. 15, n. 2, pp. 7-21.

TROVÃO, C. J. B. M.; ARAÚJO, J. B. (2018). O mercado de trabalho após a reforma trabalhista de 2017. Carta Social e do Trabalho, v. 1, pp. 32-45.

(2020). Reformas trabalhistas, flexibilização e novas formas de contratação: impactos sobre o mercado de trabalho no Brasil de 2012 a 2019. RBEST: Revista Brasileira de Economia Social e do Trabalho, v. 2, n. 00, e020009. DOI: https://doi.org/10.20396/rbest.v2i00.13304.

VILLELA, F. F. (2008). Indústria da Construção Civil e reestruturação produtiva: as novas tecnologias e a construção das cidades contemporâneas. Perspectivas - Revista de Ciências Sociais. São Paulo, v. 34, pp. $37-51$. 